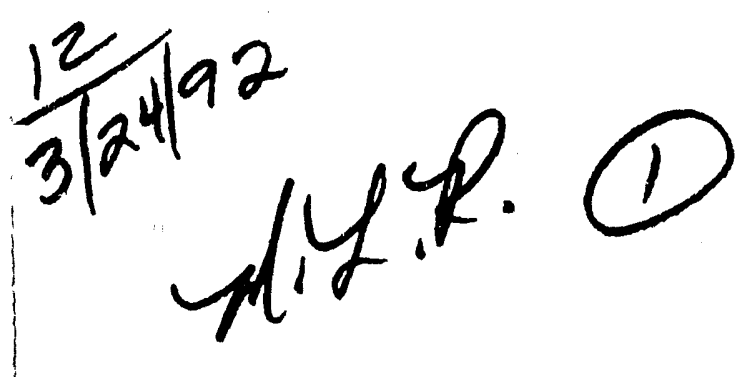

\title{
An Economic and Technical Assessment of Black-Dross- and Salt-Cake-Recycling Systems for Application in the Secondary Aluminum Industry
}

Energy Systems Division Argonne National Laboratory

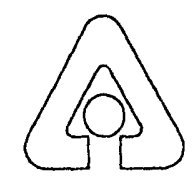

Operated by The University of Chicago, under Contract W-31-109-Eng-38, for the United States Department of Energy 


\section{Argonne National Laboratory}

Argonne National Laboratory, with facilities in the states of Illinois and Idaho, is owned by the United States govemment, and operated by the University of Chicago under the provisions of a contract with the Department of Energy.

This technical report is a product of Argonne's Energy Systems Division.

For information on the division's scientific and engineering activities, contact:

Director, Energy Systems Division

Argonne National Laboratory

Argonne, Illinois 60439-4815

Telephone (708) 252-3724

\section{Disclaimer}

This report was prepared as an account of work sponsored by an agency of the United States Govermment. Neither the United States Government nor any agency thereof, nor any of their employees, makes any warranty, express or implied, or assumes any legal liability or responsibility for the accuracy, completeness, or usefulness of any information, apparatus, product, or process disclosed, or represents that its use would not infringe privately owned rights. Reference herein to any specific commercial product, process, or service by trade name, trademark, manufacturer, or otherwise, does not necessarily constitute or imply its endorsement, recommendation, or favoring by the United States Govemment or any agency thereof. The views and opinions of authors expressed herein do not necessarily state or reflect those of the United States Government or any agency thereof. of Scientific and Technical Information, P.O. Box 62 Oak Ridge, TN 37831; prices available from (615) 576-8401, FTS 626-8401.

Available to the public from the National Technical Information Service, U.S. Department of Commerce, 5285 Port Royal Road, Springfield, VA 22161. 

and Salt-Cake-Recycling Systems for Application in the Secondary Aluminum Industry

by D. Karvelas, E. Daniels, B. Jody, and P. Bonsignore

Energy Systems Division,

Argonne National Laboratory, 9700 South Cass Avenue, Argonne, Illinois 60439

December 1991

Work sponsored by United States Department of Energy,

Assistant Secretary for Conservation and Renewable Energy, Office of Industrial Technologies 


\section{Contents}

Abstract........................................................................ 1

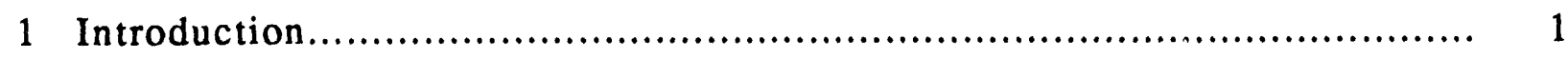

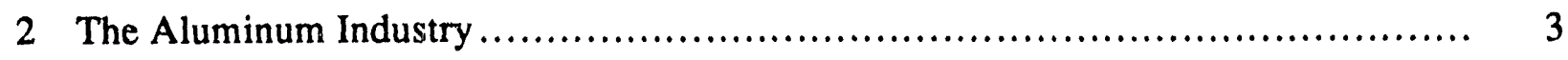

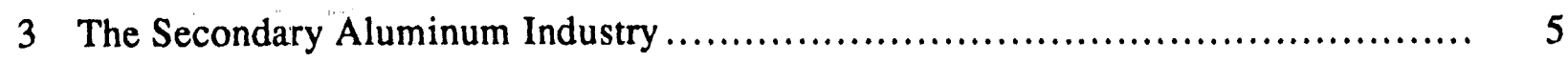

3.1 Sources and Types of Scrap Consumed.................................... 5

3.2 Processes for the Recovery of Scrap Aluminum............................... 5

3.2.1 Melting Furnaces ....................................................... 5

3.2.2 Fluxing and Dross Formation ........................................ 6

3.3 Types of Wastes Generated and Current Methods of Disposal................. 7

3.4 Alternative Methods/Technologies for Recycling Black Dross

and Salt Cake.................................................................. 9

3.4.1 Salt-Cake-Recycling Systems Developed in Europe.................... 10

3.4.2 Dross- and Salt-Cake-Recycling Systems Developed in the

United States......................................................... 13

4 Review and Evaluation of Innovative Concepts for Recovering Salt from Dross and Salt Cake.......................................................... $\quad 20$

4.1 Freeze Crystallization .................................................. 20

4.2 Solvent/Antisolvent Extraction................................................ 23

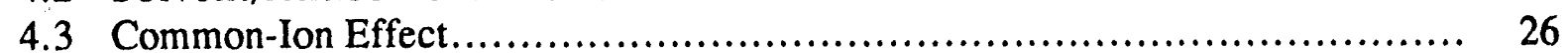

4.3.1 Addition of Hydrochloric Acid .................................... 26

4.3.2 Addition of Lithium Chloride........................................ 26

4.4 High-Temperature/High-Pressure Process................................... 26

4.4.1 Process Concept................................................. 27

4.4.2 Advantages of Operating with High-Temperature, Compressed-

Liquid Water .................................................... 28

4.4 .3 Conceptual Design .............................................. 29

4.5 Capillary-Effect Systems ............................................... 29

5 Approaches to the Use of Aluminum-Oxide Waste in the Secondary

Aluminum Scrap-Metal-Reclamation Industry................................... 31

5.1 The Bayer Process................................................... 31

5.1.1 Current Technology for Processing Aluminum Metal ................. 31

5.1.2 Suitability of Aluminum Oxide-Rich Dross and Salt-Cake Slag ........ 31 


\section{Contents (Cont'd)}

5.2 Purified Aluminum Chloride ............................................... 32

5.2.1 Commercial Production of Aluminum Chloride......................... 32

5.2.2 Suitability of Aluminum Oxide-Rich Dross or Salt-Cake Slag......... 33

5.3 Economics of Technologies for the Recycling of Black Dross and Salt Cake

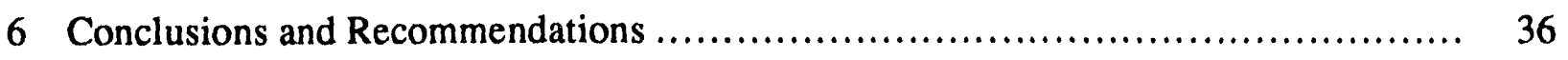

References.................................................................. 37

Figures

1 Sources of Aluminum in the United States.................................... 3

2 Scrap-Aluminum-Recycling Process ........................................ 7

3 Dross-Processing Flow Diagram .......................................... 8

4 The U.S. Bureau of Mines Process for Recovering Salt Flux from

Aluminum Dross/Salt Cake ............................................... 14

5 Flow Process of the Plasma Dross-Treatment Technology .................... 17

6 Schematic of the Plasma Torch............................................. 17

7 Typical Mass Balance for Nitrogen Plasma................................. 18

8 Typical Mass Balance for Air Plasma.......................................... 19

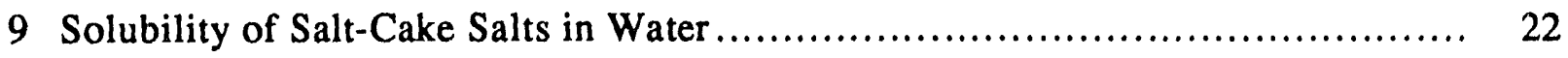

10 Comparison of the Solubility of Different Salts and Salt Mixtures in Water ....... 22

11 Effect of Various Water-Miscible Solvents on Salt Precipitation .................. 24

12 Diagram of the Hybrid Evaporation/Solvent-Precipitation System.................... 25

13 High-Temperature Solubility Data of Sodium and Potassium ................... 27

14 Diagram of the High-Temperature, High-Pressure Process ..................... 28 


\section{Figures (Cont'd)}

15 Conceptual Design of a Capillary-Effect/Diffusion-Enhanced Dryer .............. 30

16 Economics of a Typical Wet-Process System vs. Aluminum Concentration......... 35

17 Break-Even Landfill Costs of Recycling Low-Aluminum-Concentration Black Dross/Salt Cake

\section{Tables}

1 Amounts of Aluminum Scrap Consumed and Recovered, 1985-1989............... 4

2 Major Residues from Secondary Aluminum-Processing Operations in 1988......... 9

3 Estimated Costs of the Engitec Salt-Cake-Recycling System ....................... 11

4 Estimated Costs of the U.S. Bureau of Mines System.......................... 15

5 Summary of the Results of the Plasma Pilot-Plant Operation .................... 18

6 Results of Salt Precipitation Tests Conducted with Water-Miscible Solvents ......... 25

7 Estimated Costs of Processing Black Dross and Salt Cake........................ 34 


\title{
An Economic and Technical Assessment of Black-Dross- and Salt-Cake-Recycling Systems for Application in the Secondary Aluminum Industry
}

\author{
by \\ D. Karvelas, E. Daniıls, B. Jody, and P. Bonsignore
}

\begin{abstract}
The secondary aluminum industry annually disposes of large amounts of dross residues and salt cake, which are by-products from the processing of scrap aluminum for reuse. These wastes contain as much as $50 \%$ salts and are presently disposed of in conventional landfills. As the costs of landfill space increase and the availability of landfill space decrease,s, disposal of these residues will increasingly compromise the economics of recycling aluminum. Alternative processes exist by which the major constituents of the various drosses and salt cakes can be recovered for recycling. In this study, we review available recycling technologies and processes relevant to the recycling of black dross and salt cake and discuss new concepts that have the potential to improve the cost-effectiveness of recycling technologies.
\end{abstract}

\section{Introduction}

Dross and salt cake are two major waste by-products in the production of secondary aluminum. In the United States, scrap-aluminum smelters melt scrap in open-hearth reverberatory furraces. The molten aluminum in the reverberatory furnace is covered with molten salt flux. Such molten salt serves the multiple purposes of stripping the oxide from the molten metal, protecting the aluminum from further oxidation, and holding inclusions in suspension so that clean metal can be recovered. Before the molten metal is trapped, the top layer, which consists of aluminum oxide solids, spent flux, entrapped metal, and other contaminants, must be skimmed. This top layer of dark-colored material is generally called black dross. Typically, black drosses contain aluminum metal (10-20\%), a salt-flux mixture (40-55\%), and aluminum oxide (20-50\%). Depending on the market price of aluminum and its cost of transportation, black dross can be processed to recover approximately $20 \%$ of the remaining metal by means of salt bath rotary furnaces or hammer mills, which physically separate aluminum from the dross. When the recovery of aluminum from dross is not economically justifiable, it is disposed of in landfills.

Low-grade scrap that includes black dross is melted in rotary furnaces. The residues that are generated by rotary furnaces are referred to as salt cake, which contains $3-5 \%$ aluminum, $15-30 \%$ aluminum oxide, $30-55 \%$ sodium chloride, and $15-30 \%$ potassium chloride. In 1988 , 
$229 \times 10^{3}$ tons of black-dross and salt-cake residues was generated from U.S. secondary aluminum smelting plants (Moskowitz 1989).

Currently, the residues of black dross and salt cake are disposed of in solid-waste landfills. Because of increasing local environmental and institutional barriers to the development of new landfills, landfill space for the disposal of black-dross and salt-cake residues is expected to become scarce and costly.

The secondary aluminum industry is a small but crucial industry; it contributes to significant energy savings and provides economic and ecological benefits. Because the number of environmental pressures and regulations is rapidly increasing, waste management in the secondary aluminum industry has become increasingly costly in recent years. To comply with changing regulations, the industry could face substantial costs; for the industry to survive and compete successfully, it will need to employ innovative processes and technologies that conserve energy and reduce the amount of wastes generated and disposed of in landfills. In this study, we review available recycling technologies and processes relevant to the recycling of black dross and salt cake. Innovative concepts for improving the economics of recycling are also discussed. 


\section{The Aluminum Industry}

Aluminum metal is supplied by two distinct aluminum-production sectors: primary aluminum producers and secondary aluminum smelters. These sectors differ with respect to the following: raw materials used, metallurgical processing technology, markets, energy consumption, and environmental ramifications. The primary aluminum industry in the United States produces aluminum mostly from mined ore (bauxite). Some scrap is also used, which is usually from recycled aluminum beverage cans and industrially generated high-grade aluminum scrap. In 1989 , the total supply of U.S. aluminum was estimated at $8.2 \times 10^{6}$ tons, and primary producers produced more than 54\% of this supply (Aluminum Recycling Association 1990). The sources of aluminum in the United States for 1989 are shown in Fig. .

The reclamation of aluminum cans - a major source of scrap for the primary aluminum industry - has increased substantially in the last fifteen years. The continuing growth in aluminum can recycling has increased the value of aluminum, yielded energy savings, and resulted in ecological benefits. In 1989 , more than $60 \%$ of the shipped aluminum cans were recycled; in contrast, in 1975 , about $27 \%$ of the shipped aluminum cans were recycled.

Aluminum recycling saves resources at every step of primary production, from the mining of bauxite through the energy-intensive processes of aluminum recovery. Recycling $1 \mathrm{lb}$ of aluminum can save about $4 \mathrm{lb}$ of bauxite, $2 \mathrm{lb}$ of chemicals, and $7.5 \mathrm{kWh}$ of electricity (Aluminum Recycling Association 1988). In 1989, the nearly $2.25 \times 10^{6}$ tons of aluminum that was recycled saved about $9 \times 10^{6}$ tons of bauxite, $4 \times 10^{6}$ tons of chemicals, and $34 \times 10^{9} \mathrm{kWh}$ of electricity.

Secondary aluminum producers are entirely dependent on scrap for raw material; in 1989, they used about $37 \%$ of the aluminum scrap recycled in the United States (Aluminum Recycling

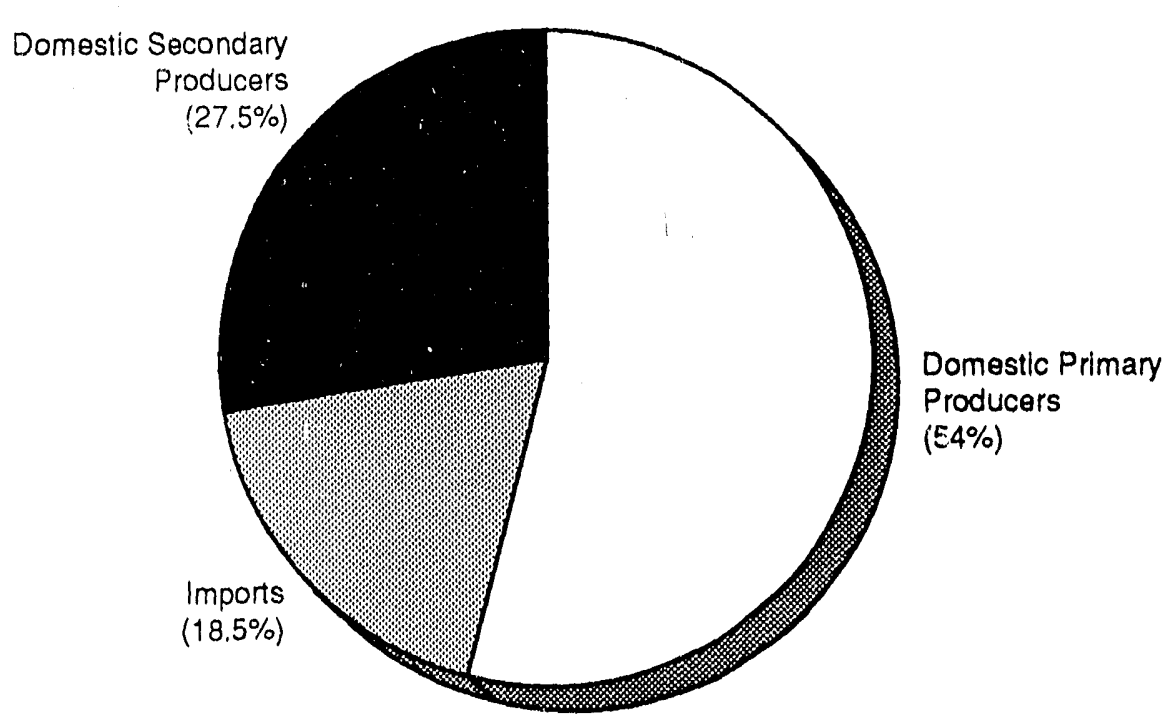

FIGURE 1 Sources of Aluminum in the United States. Source: Adapted from Aluminum Recycling Association (1990). 
Association 1990). The main product of the secondary aluminum industry is aluminum ingot, which is primarily used by aluminum foundries to produce castings (such as master cylinders and oil pans for automotive applications) and motor housings for lawn mowers. Table 1 shows the amounts of aluminum scrap consumed and recovered by the primary and secondary aluminum industries.

TABLE 1 Amounts of Aluminum Scrap Consumed and Recovered, 1985-19894

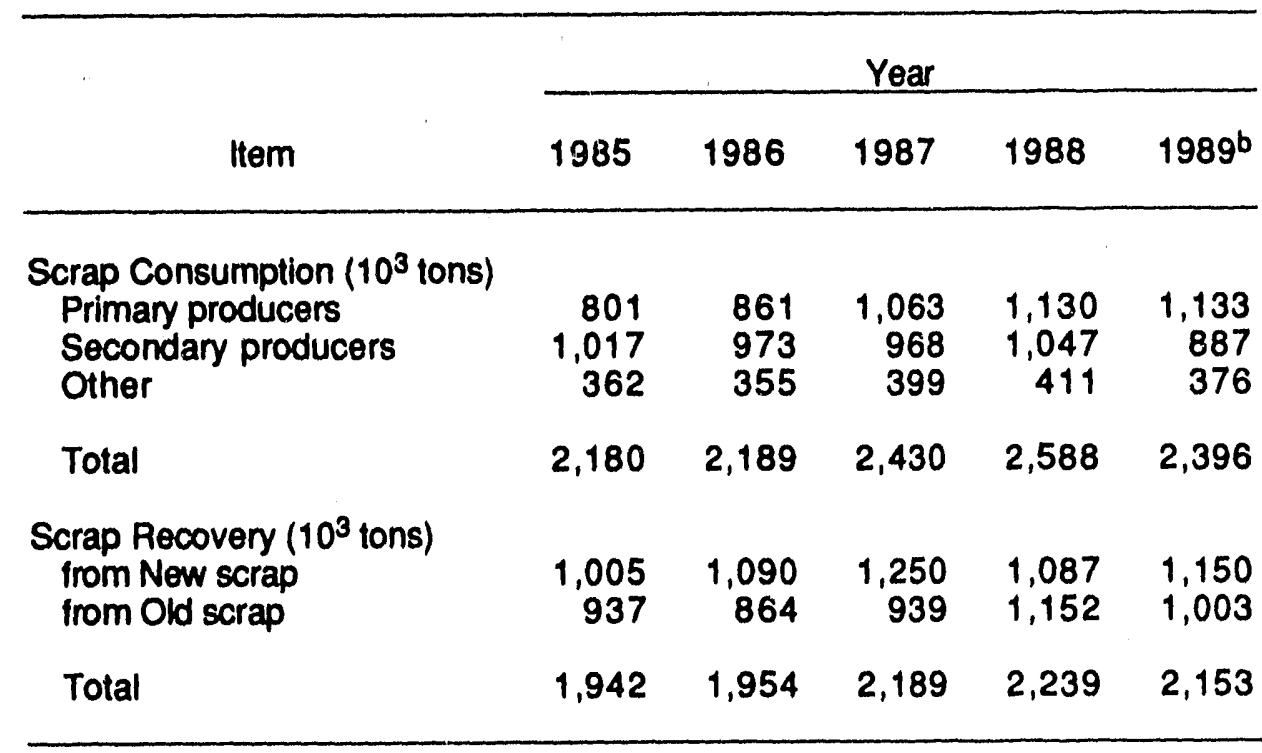

aAluminum Recycling Association (1989).

bEstimated. 


\section{The Secondary Aluminum Industry}

The key elements that comprise the commercial secondary aluminum industry are principally scrap collection, processing, and smelting. This report reviews current smelting processes and technologies, including those for recycling salt siags, to determine their technical and economic effectiveness fo: minimizing the generation of salt-based wastes.

\subsection{Sources and Types of Scrap Consumed}

Aluminum scrap, the raw material of the secondary aluminum industry, is a by-product of fabricating operations or a product of obsolescence. Each smelter segregates the scrap into four main categories: sheet and castings, clippings and other solids, borings and turnings, and residues (dross, slag, and skimmings). Each type of scrap has unique chemical and physical characteristics, and the value of the scrap is determined by the level of impurities contained in the scrap and the cost of recovering the metal. And because each type of scrap requires specialized equipment, few smelters are equipped to process all four types of scrap.

\subsection{Processes for the Recovery of Scrap Aluminum}

To produce aluminum metal that meets the casting industry's specifications, the scrap metal must be melted, blended, cleaned, refined, and cast into alloys of s pecified chemical composition. The tasks for the recovery and refinement of aluminum from scrap metal are conducted while the scrap is being charged and melted in the reverberatory and rotary furnaces.

\subsubsection{Melting Furnaces}

Reverberatory and rotary furnaces are the two most common types of furnaces used by the secondary aluminum industry in the United States. Reverberatory furnaces range in capacity from $30 \times 10^{3} \mathrm{lb}$ to $250 \times 10^{3} \mathrm{lb}$ of molten metal. In most cases, the charge on the floor or hearth of the reverberatory furnace chamber is heated by convection and radiation from the flame above it. In the melting process, the scrap is charged into the furnace. The furnace fuel may be either natural gas or fuel oil. The metal recovery rate in a reverberatory furnace can be as high as $90 \%$.

The rotary furnace is primarily used in the United States to melt low-grade scrap, such as drosses and sweated pig. In European smelting operations, the rotary furnace is used for all scrap smelting, but interest in reverberatory furnaces has been increasing because of its energy efficiency and lower flux requirements (compared with rotary furnaces). Because the process of recovering aluminum from low-grade scrap requires large quantities of salt, rotary furnaces generate large quantities of salt cake. For every pound of low-grade scrap charged into the rotary furnace, one pound of salt flux is typically used. 


\subsubsection{Fluxing and Dross Formation}

An important step in the process of recovering aluminum from scrap is fluxing to remove metal oxides and other impurities. Because of aluminum's extreme reactivity on exposure to the atmosphere, an aluminum-oxide film is formed on the surface, which serves as an effective barrier to further reaction. Every piece of aluminum charged into the furnace has a thin surface film of oxide. During the melting of scrap aluminum, the formation of additional oxide on the surface of the molten metal is unavoidable, unless melting is accomplished in an oxygen-starved atmosphere, which is not economically feasible. Reactions with the furnace atmosphere form not only aluminum oxide, but also other nonmetallic impurities (such as nitrides, carbides, and other oxides) and oxynitride spinels, thus compounding the oxide problem.

Prior to the removal of the melt from the furnace, a hoe-like device, attached to a forklift truck or similar machine, can be used to skim the impurities formed on the surface of the molten metal. The skim or layer of dross of the unfluxed bath can contain a substantial amount of entrained metal, often $15-80 \%$ metallic aluminum (trapped as droplets). A thin oxide film on the surface of the droplets prevents them from coalescing and combining with the metal in the bath.

To minimize metal oxidation of the liquid metal and, most importantly, effect separation of the metal from the dross, standard practice has been to use a cover of molten salt "flux" on the surface of the liquid metal in the charging well. Fluxing is best performed in the charging well of the furnace; the scrap is charged through the molten flux layer in order to minimize oxidation. As the flux layer becomes viscous, it is removed and new flux is added. In addition to minimizing oxidation, the application of flux reduces the force of adhesion between the oxides and the metal surface in the dross, which enhances the rate of coalescence of the entrapped aluminum droplets, allowing the molten aluminum to return more efficiently into the melt pool. The mechanisms by which the salt "flux" strips the oxide from the metal and holds the solius in suspension are not well understood.

The secondary aluminum industry has developed fluxes, of various chemical compositions, that are believed to be effective in refining and reducing metal loss when various types of scrap and drosses are smelted. More than 100 flux compositions are available to scrap-aluminum smelters, but the most commonly used fluxes are mixtures of $\mathrm{NaCl}$ and $\mathrm{KCl}$ in approximately equal amounts, to which 3-5 weight percent (wt. \%) cryolite is added (Rao and Dawson 1980). The advantages of this chloride mixture (as a fluxing agent) are its low cost ( $\$ 100 /$ ton) and low melting point. Sodium chloride is lower in cost, but potassium salts have lower viscosity and lower surface tension, qualities that increase fluidity. The melting point of this mixture is just below the melting point of aluminum $\left(660^{\circ} \mathrm{C}\right)$. It is important that the melting point of flux is below the melting point of aluminum, because during heating of the charge, the salt melts first and coats the aluminum before the metal melts, thereby protecting the metal from further oxidation. The cryolite seems to function as a "wetting" agent, improving the molten aluminum metal's ability to coalesce into larger globules.

The amount of flux used in the reverberatory furnace to recover aluminum from scrap depends on the amount of impurities contained in the scrap. For each pound of impurities charged to the furnace, approximately one pound of flux is used. In a rotary furnace, because it is mostly 
used to melt low-grade scrap, considerably more flux is used. For dross processing, one pound of flux is used for each pound of dross concentrate charged to the rotary furnace.

\subsection{Types of Wastes Generated and Current Methods of Disposal}

The main sources of wastes in secondary aluminum-smelting operations are the impurities in the aluminum scrap, oxicies formed during melting, and the salt flux used to reduce metal loss. The salt flux used in scrap-alumirum smelting ends up in the black dross and salt cake, which are commonly disposed of in landfills. Figure 2 is a diagram of the recycling process for scrap aluminum and the various sources of waste generation.

The secondary aluminum industry faces two major environmental constraints: (1) the disposal of wastes high in salt content generated from smelting scrap in reverberatory furnaces and (2) the disposal of wastes generated fre the treatment of low-grade scrap in rotary furnaces. The wastes generated in secondary aluminum plants are chraracterized according to their chemical composition and source. Three primary types of wastes are generated in large quantities: blackdross residues, salt cake, and furnace baghouse dust. Black dross is referred to as the high-salt dross that is removed from the top of the meli in the reverberatory furnace. Typically, black dross contains aluminum (12-20\%), sodium chıoide (20-25\%), potassium chloride (20-25\%), aluminum oxide (20-50\%), and other compounds (2-5\%).

The black dross constitutes up to $20 \%$ of the melt charge and contains relatively large amounts of metallic aluminum. In 1988, approximately $114 \times 10^{3}$ tons of black dross was generated (Moskowitz 1989). Black drosses are most often further processed to recover as much as $80 \%$ of the remaining aluminum. In orcler to recover the aluminum and make recycling economically justifiable, the dross must be upgraded (usually by means of milling and screening) at least to $50 \%$ aluminum concentrate. Because the metal is less brittle than the other dross constituents, it will not break in the milling process, and it will tend to be screened out in the

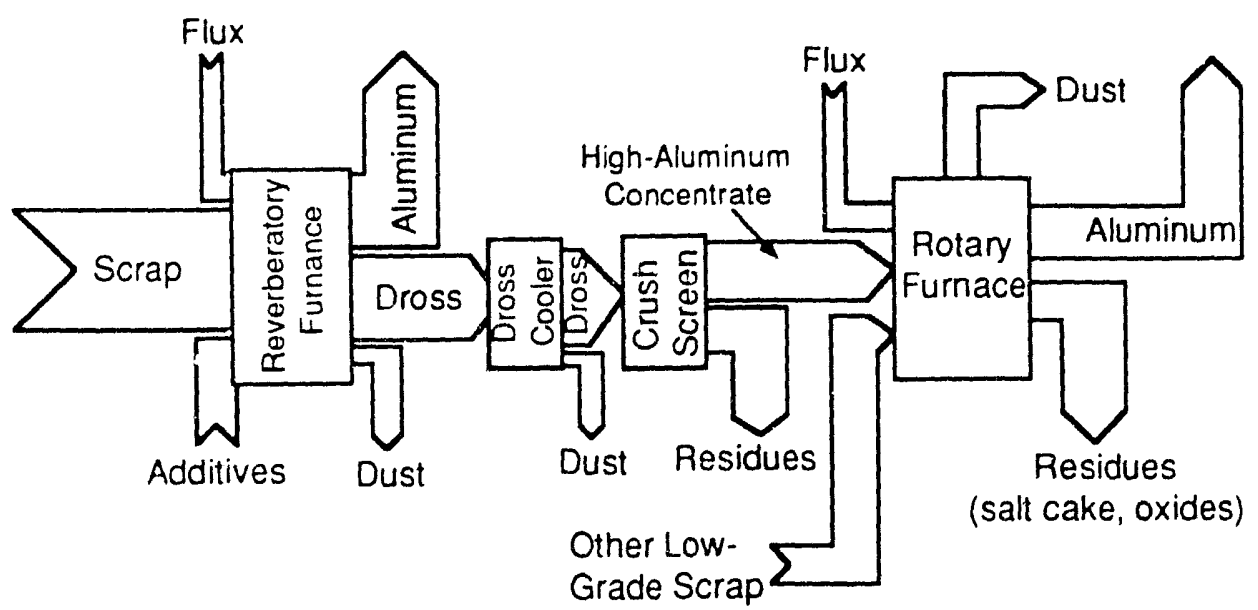

FIGUF 2 Scrap-Aluminum-Recycling Process 
coarser fractions. The coarser fractions represent as low as $15 \%$ of the total weight of the milled dross and can contain as much as $80 \%$ metallic aluminum. The aluminum "concentrate" is processed in a rotary furnace for the recovery of the aluminum.

The finer-sized fractions, less than about 20 mesh, can represent up to $85 \%$ of the milled black dross. The finer fractions can contain as much as $10 \%$ metallic aluminum. Some highermetallic, finer-sized fractions have been marketed to the exothermic market when blended with other low-chloride, high-metallic fines. The exothermic market is very limited, and it does not contribute significantly to industry's revenues. In 1988, approximately $17 \times 10^{3}$ tons of aluminum was recovered from dross. A general dross-processing flow diagram is shown in Fig. 3.

The salt cake generated from the rotary furmaces ranges up to $75 \%$ of the melt charge in rotary furnaces. In 1988, about $114 \times 10^{3}$ tons of salt cake was generated, of which very little, if any, was recycled; most of it was disposed of in landfills (Moskowitz 1989). The salt cake consisted of aluminum (1-5\%), aluminum oxide (15-30\%), sodium chloride (30-55\%), potassium chloride (15-30\%), and inert compounds (1-4\%). Table 2 lists the estimated total amount of solid residues generated by the secondary aluminum industry in 1988 from secondary aluminumproduction operations (Moskowitz 1989).

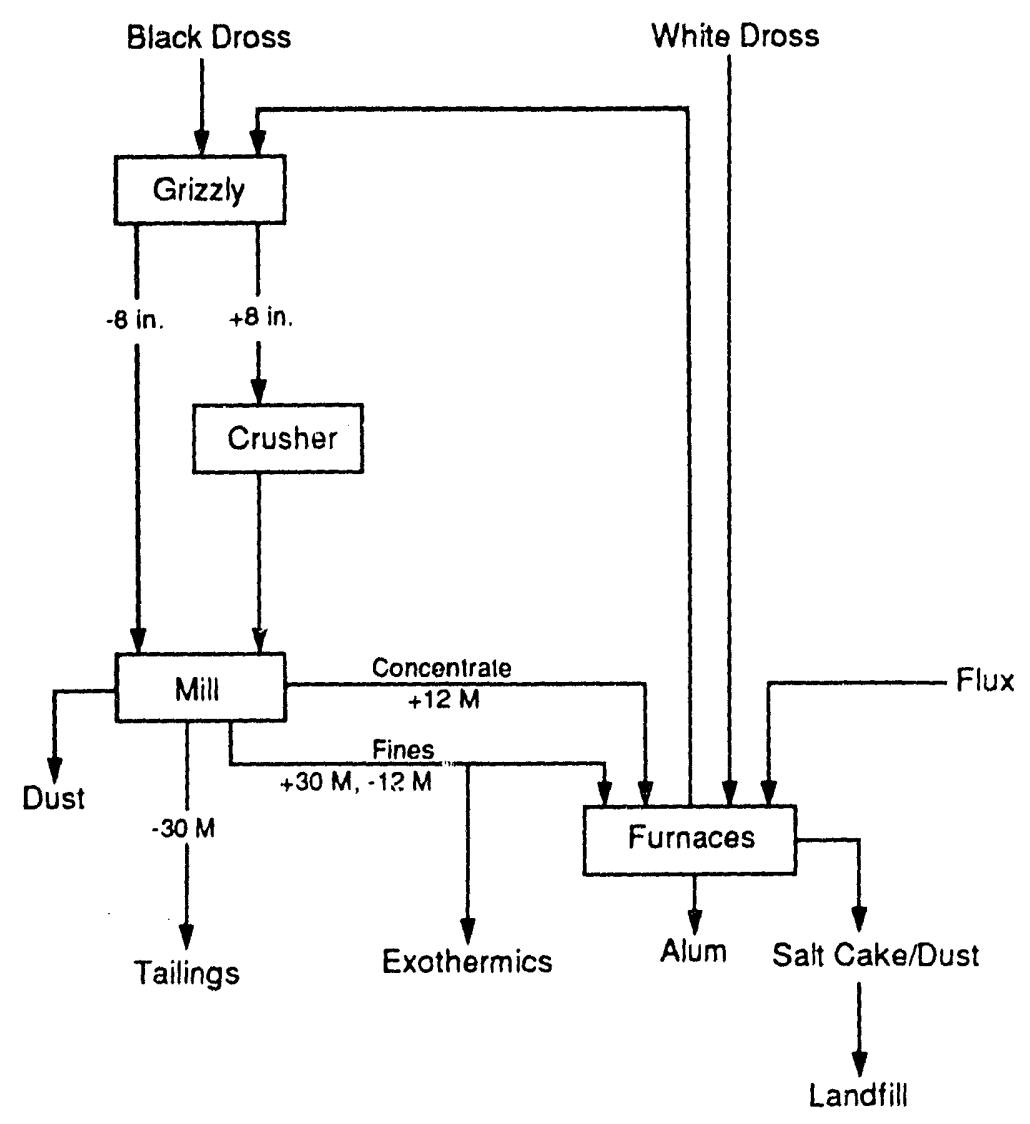

FIGURE 3 Dross-Processing Flow Diagram. Source: Adapted from Kulik and Daley (1990) 
The amount of baghouse dust generated by the secondary smelting industry is estimated at about $10^{4}$ tons/yr. Black dross and salt cake, with few exceptions, are not classified as toxic or hazardous wastes. Baghouse dust generated at scrap-aluminum melting operations may contain levels of heavy metals and other impurities that may need to go through a detoxification treatment in order to render them nonhazardous. The scrap-aluminum smelting plants do not treat hazardous wastes on-site; treatment is mostly carried out by the landfill operator or by other commercial operators. In the future, the disposal fees for hazardous wastes are projected to increase significantly, and large smelters may find it economically justifiable to install on-site facilities for the treatment of hazardous waste. Currently, the disposal fees for hazardous industrial wastes are as high as $\$ 450 /$ ton.

\subsection{Alternative Methods/Technologies for Recycling Black Dross and Salt Cake}

Historically, the processes that have been developed and employed for the recovery of aluminum from scrap aluminum have focused on maximizing aluminum recovery at minimum cost. The disposal of waste by-products did not constitute a major cost in aluminum production, and there was no incentive to recycle reusable constituents of the waste products. In the last few years, however, public awareness of and concerns about the quality of the environment have forced federal and local lawmakers to pass strict regulations on air pollution and on the disposal of various industrial wastes. The cost of these regulations to all industries has been substantial; in the future, more stringent regulations are likely to be instituted because many communities are becoming very active and vocal with regard to environmental issues. The increasing number of environmental regulations has forced the secondary aluminum industries in Europe and the United States to consider recycling technologies for the reduction of waste.

Technologies for the recycling of black dross and salt cake have been employed by U.S. and European smelters to recycle the salts, recover some aluminum, and generate a waste product (oxides) that can be easily disposed of in conventional landfills. These technologies would essentially leave only the oxides and impurities contained in the scrap aluminum to be disposed of. The first systems for recycling black dross and salt cake were not successful; these systems suffered from corrosion because of the highly corrosive nature of hot salt solutions in the saltrecycling stream. Interest in recycling has been stimulated by the increasing number of environmental regulations in Europe and in the United States. As a result, improved technologies for recycling dross and salt cake have been developed, and they are currently employed in Europe and are under consideration by U.S. industry. As was previously discussed, European aluminum smelters use rotary furnaces for most of their scrap-smelting operations, and the recycling 
technologies developed in Eurone were designed primarily to process salt cake, although the manufacturers claim that these systems can process dross. Salt-cake-recycling systems that have been developed and are operating in Europe are currently being marketed in the United States, but none of them have been installed in the United States.

\subsubsection{Salt-Cake-Recycling Systems Developed In Europe}

Salt-cake-recycling systems installed in Europe have been in operation for several years; the capacity of each of these systems is less than $60 \times 10^{3} \mathrm{t} / \mathrm{yr}$. Most of the systems have been installed in Germany and Italy, countries in which the disposal of salt cake in landfills is not permitted. The manufacturers of these systems claim to have learned a lot from the operation of smaller prutotype systems; therefore, they are able to design systems with much higher capacities than would be suitable for the U.S. market.

Two European salt-cake-recycling systerns, discussed below, being marketed in the United States are manufactured by (1) Engitec Impianti S.p.A. of Italy ${ }^{*}$ and (2) Berzelius Umwelt-Service A.G. (B.U.S.) of Germany. ${ }^{\dagger}$ Similar technology has also been developed by Sulzer-Escher Wyss of Switzerland.

\subsubsection{The Engitec System}

The Engitec system was designed to process salt cake. Engitec installed its first system in 1977 , in Italy, and this system is capable of recovering $21 \times 10^{3} \mathrm{t}$ of salt per year from a brine solution stored in an old evaporation pond at a secondary aluminum-smelting plant. This recycling plant was completely renovated in 1988 , at which time an evaporator/crystallizer unit with mechanical vapor recompression was added. Recently, another small system was installed in Brazil, but details about the design and application of this system are not known. Since 1988, Engitec has claimed that pilot testing has been completed at its research facilities on a flashevaporator system to be used with small recycling plants and on a preconcentration unit for largecapacity evaporator/crystallizer systems. A proposed 60-t/day salt-cake-recycling design, based on the engineering design parameters developed from the operation of a small $(2 \mathrm{t} / \mathrm{d})$ pilot plant, is described below.

The process used in recovering salt from salt cake consists of the following process steps (Reynolds et al. 1990):

1. Crushing and screening,

2. Leaching/filtering,

*U.S. representative: Lake Engineering, Inc.

†U.S. representative: Horsehead Resource Development Co., Inc. 
3. Gas elimination and brine purification, and

4. Evaporation/crystallization.

In the crushing and screening operation, fractions less than $1.5 \mathrm{~mm}$ in size with negligible aluminum are sent to the reaction tanks for the production of salt brine. The baghouse dust from the sireening operation is also sent to the reaction tanks. The crushed fines and dust are reacted with make-up water and hot recycled water, and the materials are leached to produce a brine solution with a concentration of approximately $25 \%$ by weight sodium/potassium chloride. The slurry of reacted and concentrated brine is pumped to a vacuum belt filter. The filtered aluminumoxide fines have moisture contents of approximately $25-30 \%$. The filter cake is washed on the belt filter with recycled water and fresh water to achieve a chloride content of less than $0.5 \%$.

In the purification process (to produce a very clean brine), chemicals are added that strip the ammonia and remove the calcium and magnesium by precipitation and filtration. The various gases produced from leaching and other system operationis are burned in an afterburner, producing water, nitrogen, carbon dioxide, phosphoric acid, and sulfur dioxide. These compounds pass to the flash evaporator, within which they are mixed with excess chemicals from the purification step. The materials are precipitated and filtered before they enter the crystallizer. After filtration, the brine is transferred to the flash evaporator for preconcentration. The preconcentrated solution is separated from the gases by a cyclone and directed to a holding vessel. The solution is then filtered by a filter press, stored in a storage tank, and pumped through two heat exchangers into a drafttube baffle evaporator/crystallizer. The evaporator/crystallizer uses mechanical vapor recompression (MVR). The material is circulated through the evaporator/crystallizer, and a small stream of salt crystals is removed from the bottom of the crystallizer. The crystals are sent to a centrifuge and recovered as salt crystals.

The system described above has not been built by Engitec; the design was based on engineering data developed from laboratory-scale, pilot-plant experiments. Engitec has estimated the capital and operational costs for 60 - and 200-t/day systems; these costs are summarized in Table 3.

TABLE 3 Estimated Costs of the Engitec Salt-CakeRecycling System

\begin{tabular}{lcc}
\hline \multicolumn{1}{c}{ Item } & System A & System B \\
\hline Capacity (t/d) & 60 & 200 \\
Salt cake processed $\left(10^{3}\right.$ tyr) & 19.8 & 66 \\
Capital cost (\$/ processed) & 250 & 150 \\
Annual days of operation & 330 & 330 \\
Operating cost (\$/t) & 57 & 33 \\
\hline
\end{tabular}




\subsubsection{The Berzellus Umwelt-Service A.G. System}

The Berzelius Umwelt-Service A.G. (B.U.S.) system can process both dross and salt cake. The first system developed by this German manufacturer was installed in Germany, and it has been in operation for four years. The system was designed to process $50 \times 10^{3}$ tons of salt cake and $13 \times 10^{3}$ tons of ball mill dust per year. At the time that this report was written, this plant had processed more than $240 \times 10^{3}$ tons of salt cake and ball mill dust. The salt cake processed at this plant is supplied by five secondary aluminum smelters and contains, on average, $7 \%$ metallic aluminum. A B.U.S. representative to the United States anticipates that by the end of 1991 , two more plants will be in operation in Germany, bringing the total annual operating capacity of the plant to more than $260 \times 10^{3}$ tons. The process used by the B.U.S. system consists of the following process steps (Unger and Hanrahan 1990):

1. Grinding and screening,

2. Leaching,

3. Gas treatment,

4. Solid-liquid separation, and

5. Crystallization.

During the grinding and screening phase, more than $80 \%$ of the salt cake fed to the plant is reduced to less than $1 \mathrm{~mm}$ in size, while the remaining material is treated in several stages of roller mills to increase the rate of recovery of aluminum metal. The fines are leached in a closed tank using only condensate from the crystallization-evaporation system. The leaching tank and the gastreatment system are operated under vacuum in order to prevent harmful and poisonous components of the material from escaping into the atmosphere. As the explosive gases (hydrogen and methane) are formed, they are diluted as fresh air is mixed with them. The gas-treatment process includes the following components:

1. A dust separator, designed as a wet scrubber;

2. A chemical column in which ammonia is mainly precipitated as ammonium sulfate by sulfuric acid; and

3. A double-stage active carbon adsorption area.

In the first stage of the adsorbers, most of the remaining hydrogen sulfide is completely adsorbed; in the second stage, the amounts of phosphine, arsenin, and hydrogen selenide are removed and reduced to nearly zero. The gas-treatment process is continuously controlled and monitored by a central computer system.

In the solid-liquid separation process, a two-stage thickener is used, and the heavy suspension from the suspension tank is pumped to filter presses where the filter cake is washed 
with recycled water on the belt filter in order to achieve a soluble-salt content of less than $0.5 \%$ of the dry matter. In the crystallization operation, the concentrated brine is processed by means of a multiple-effect evaporation system or a mechanical vapor-recompression system; the choice of system depends on the least-cost energy source that is available on-site. The company's first plant for the recycling of salt cake incorporates a four-effect, forced-circulation, evaporationcrystallization system. The quality of the salt recovered from this process meets the specifications of the smelters. In the last four years, $130 \times 10^{3}$ tons of melt salt has been recovered and successfully used by eight secondary smelters.

Detailed capital and operational costs for the B.U.S. system have not been developed, although a representative from Horsehead Resource Development Co., B.U.S.'s U.S. market business partner, estimated the capital cost for a 100-t/day system to be about $\$ 35,000,000$ (Roy 1990).

\subsubsection{Dross- and Salt-Cake-Recycling Systems Developed in the United States}

\subsubsection{The United States Bureau of Mines Experimental Dross-Recycling System}

In the late 1970s, the U.S. Bureau of Mines developed a hydrometallurgical method to recover aluminum, aluminum oxide, and fluxing salts from aluminum dross and salt cake (Magyar et al. 1980). In this method, dross or salt cake is leached with water at room temperature to produce a saturated brine slurry. The slurry is screened to yield an aluminum-rich fraction that can be returned to the dross furnace. The remaining slurry is vacuum filtered, yielding a clear brine solution and an aluminum-oxide filter cake. Evaporation of the clear filtrate produces a high-purity fluxing salt for reuse in the dross furnace. In this process, over $80 \%$ of the metallic aluminum is recovered in the aluminum-rich fraction, while essentially all of the fluxing salts are recovered by evaporation.

The method developed by the Bureau of Mines was tested on a laboratory-scale model. The test demonstrated the teshnical feasibility of leaching the salt cake and evaporating the brine in order to recover salt flux. But more importantly, the test generated data that could be used to conduct an economic evaluation for a commercial-scale operation.

On the basis of the data generated from the laboratory experiments, a commercial-scale system was designed and an economic feasibility study was conducted. The commercial-scale system was designed to process $90 \mathrm{t} /$ day of salt cake. In the economic analysis, it was assumed that no crushing equipment would be required, because the leaching tank would be replaced with a drum capable of leaching larger salt cake. A diagram of the commercial-scale system is shown in Fig. 4. The cost analysis conducted by the Bureau of Mines was based on 1977 capital and operating costs; these costs had to be revised in this study to reflect current costs. The costs of the proposed system are provided in Table 4. Since the development of the design for the 


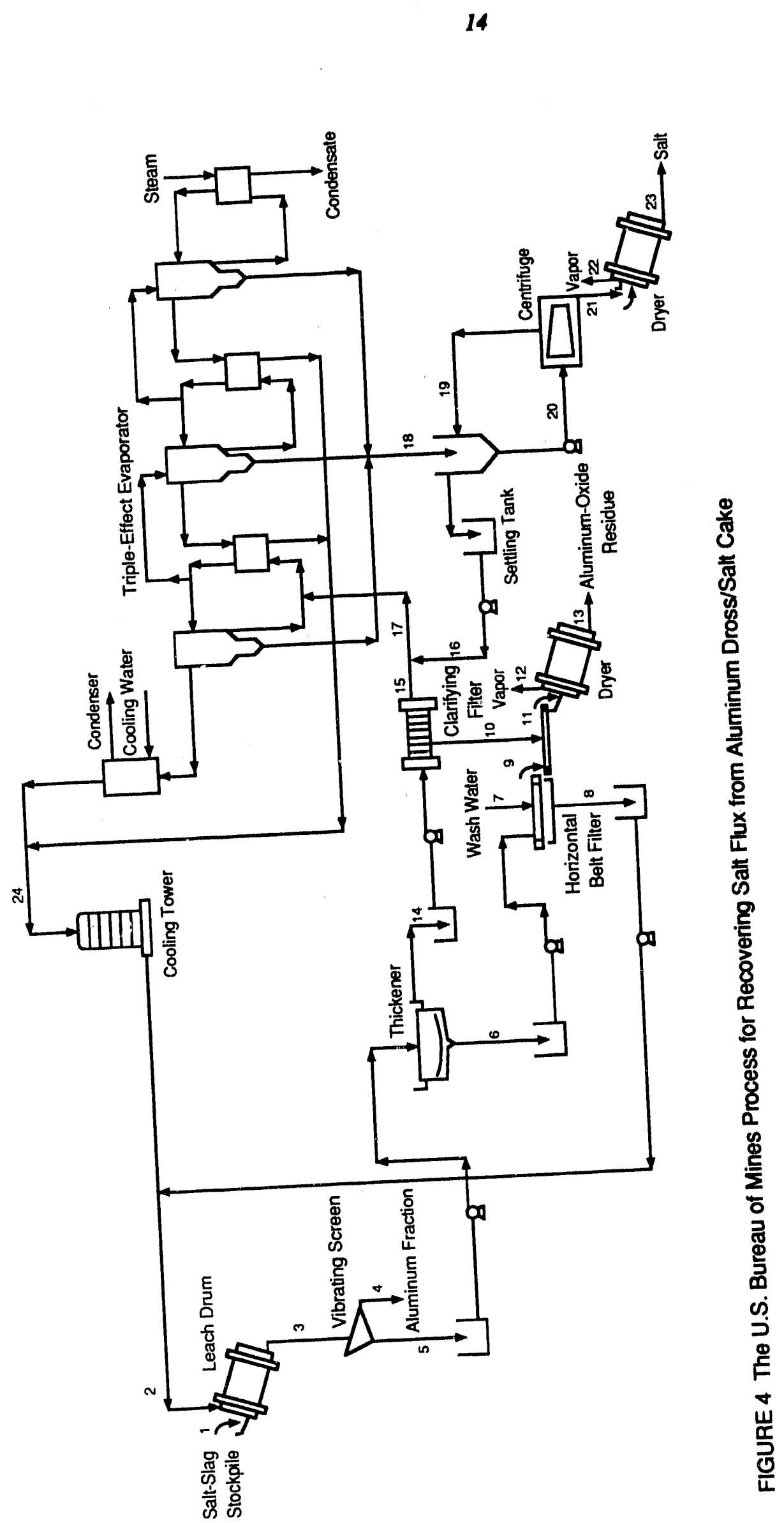


TABLE 4 Estimated Costs of the U.S. Bureau of Mines System (current dollars)

\begin{tabular}{|c|c|c|c|c|}
\hline Hem & $\begin{array}{c}\text { Unit } \\
\text { Consumption }\end{array}$ & $\begin{array}{c}\text { Cost } \\
\text { Per Unit } \\
(\$)\end{array}$ & $\begin{array}{c}\text { Total } \\
\text { Annual Cost } \\
\text { (\$) }\end{array}$ & $\begin{array}{l}\text { Unit Cost } \\
(\$ / t)\end{array}$ \\
\hline $\begin{array}{l}\text { Personnel } \\
\text { Electricity } \\
\text { Process steam } \\
\text { Oil } \\
\text { Water } \\
\text { Maintenance } \\
\text { Depreciation ( } 11 \text {-yr life) } \\
\text { Insurance ( } 1 \% \text { of capital equip.) }\end{array}$ & $\begin{array}{l}0.8 \mathrm{~h} / \mathrm{t} \\
33.6 \mathrm{kWh} / \mathrm{t} \\
2.4210^{3} \mathrm{lbHt} \\
6.96 \mathrm{galt} \\
0.59 \mathrm{~m}^{3} / \mathrm{t} \\
= \\
=\end{array}$ & $\begin{array}{l}17 / \mathrm{h} \\
0.05 / \mathrm{kWh} \\
9.50 / 10^{3} \mathrm{lb} \\
0.50 / \mathrm{gal} \\
0.26 / \mathrm{m}^{3} \\
= \\
=\end{array}$ & $\begin{array}{r}407,150 \\
50,290 \\
688,250 \\
104,030 \\
7,780 \\
449,055 \\
610,275 \\
67,180\end{array}$ & $\begin{array}{r}13.60 \\
1.68 \\
22.99 \\
3.48 \\
0.15 \\
15.00 \\
20.40 \\
2.24\end{array}$ \\
\hline Total & & & $2,384,010$ & 79.64 \\
\hline
\end{tabular}

aEstimated capital cost: $\$ 7,000,000$; capacity: $90 \mathrm{tdd}$; operation: $330 \mathrm{~d} / \mathrm{yr}, 24 \mathrm{~h}, 7 \mathrm{~d} / \mathrm{week}$; direct labor: three workers/shift.

Bureau of Mines dross/salt-cake-recycling system, air pollution regulations have become more stringent; therefore, the costs of pollution-control equipment are underestimated in the U.S. Bureau of Mines study.

\subsubsection{The American Recovery Technology Systems, Inc., Recycling System}

In Cleveland, Ohio, American Recovery Technology Systems, Inc. (ARTS), has designed, built, and is currently operating its first system for the recycling of dross and salt cake. According to information provided by the president of ARTS (Yerushalmi 1990), this system can process dross and salt cake, and the existing plant has the capacity of processing about $65,000 \mathrm{t} / \mathrm{yr}$. The closed-loop system consists of the following key processes:

1. Reduction of dross/salt cake into two fractions. In the crushing operation, the dross/salt cake is reduced into two main fractions: (1) coarse, $>10$ mesh but $<4$ in. in size (about $80 \%$ of the initial material), and (2) fines, $<10$ mesh (about $20 \%$ of the initial material).

2. Dissolution of flux salts. Water leaches the fines fraction to dissolve the flux salts and leave behind an aluminum-rich $\mathrm{Al} / \mathrm{Al}_{2} \mathrm{O}_{3}$ mixture (about 18-23\% aluminum), which can be sold as exothermic fines for $10-12$ cents/lb.

3. Digestion of coarse fraction. The coarse fraction is water digested with a solution separation of soluble flux salts. An additional quantity of fine-particlesized, insoluble, $\mathrm{Al} / \mathrm{Al}_{2} \mathrm{O}_{3}$ mixture is released, which is generally lower in 
aluminum content than the washed coarse fines, but it is still high enough to be blended and sold with higher aluminum exotherm. The remaining coarse fraction, enriched in aluminum, is sent to rotary furnaces.

4. Distillation of water from brine solution. Water from the brine solution is removed by distillation, under pressure, through the intermediacy of a heatexchange system made of titanium and monel. The temperature of the processed brine ranges from $238^{\circ} \mathrm{F}$ to $240^{\circ} \mathrm{F}$

ARTS claims that its system would be just as effective for recycling black dross.

\subsubsection{The Alcan International Limited/Plasma Energy Corporation Dross-Treatment Process}

Alcan International Limited and Plasma Energy Corporation are currently developing a dross-processing technology that does not require salt. The process uses a specially designed rotary furnace heated by a plasma arc gas heater. The principle of operation of this process is shown in Figs. 5 and 6 (Dube and Dube 1990). The working principle of the plasma torch is as follows: inside the plasma torch are two tubular electrodes placed end-to-end but separated by a small gap. During the operation, a process gas (such as air or nitrogen) is injected into the small gap between the electrodes. The arc heats the incoming gas to temperatures in excess of $5000^{\circ} \mathrm{C}$. At this temperature, the gas is dissociated and partially ionized. The ionized gas is called plasma, which is ejected out of the torch and into the rotary furnace to heat the dross.

Alcan installed its first plasma dross-treatment plant in 1988. The plasma torch is rated at $1 \mathrm{MW}$, and the rotary furnace capacity is about $3 \mathrm{t}$. The $1-\mathrm{MW}$ torch uses $1.5-3 \mathrm{~m}^{3} \mathrm{of}$ gas/min. The plant is designed to process industrial-scale samples of dross, and blocks of up to one metric ton can be charged, as can very dusty dross. The rotary furnace is designed to be airtight, and during its operation, the inside pressure is always maintained positive to prevent the infiltration of outside air.

To evaluate this dross-processing technology, Alcan has processed about $400 \mathrm{t}$ of dross, representing a total of about 150 batches. The dross was supplied from various primary and secondary aluminum-production plants in the United States, Canada, and Europe; the aluminum content of these samples ranged from $10 \%$ to $80 \%$. On the basis of the data generated from the above experiments, Alcan has developed general performance data on this new technology; the results are shown in Table 5 and Figs. 7-8.

The weight of the nonmetallic products (NMP), shown in Figs. 7 and 8, includes the weight of the baghouse dust. On average, $10.2 \mathrm{~kg}$ of baghouse dust was produced per metric ton of dross processed. Alcan estimated the typical electrical energy input into the system to be about $844 \mathrm{kWh}$ for the nitrogen plasma and $475 \mathrm{kWh}$ for the air plasma per metric ton of dross processed. 


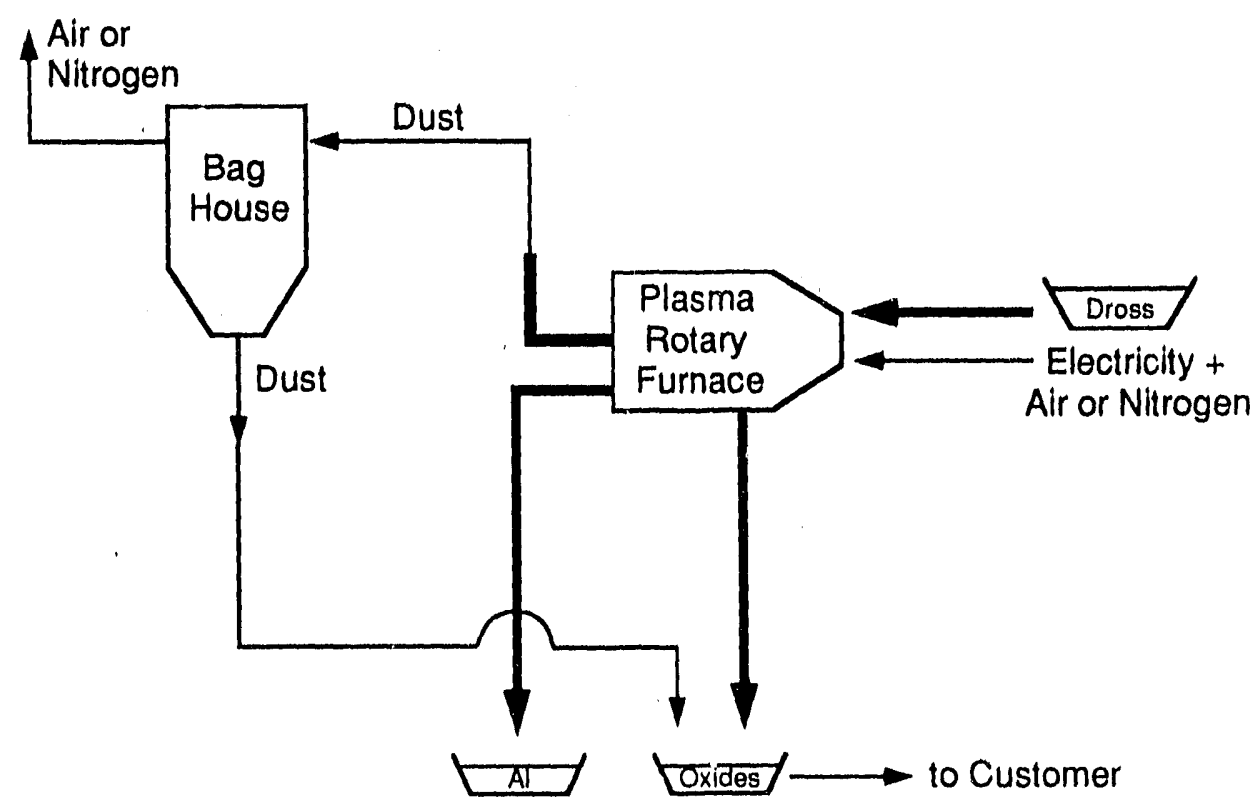

FIGURE 5 Flow Process of the Plasma Dross-Treatment Technology. Source: Adapted from Dube and Dube (1990)

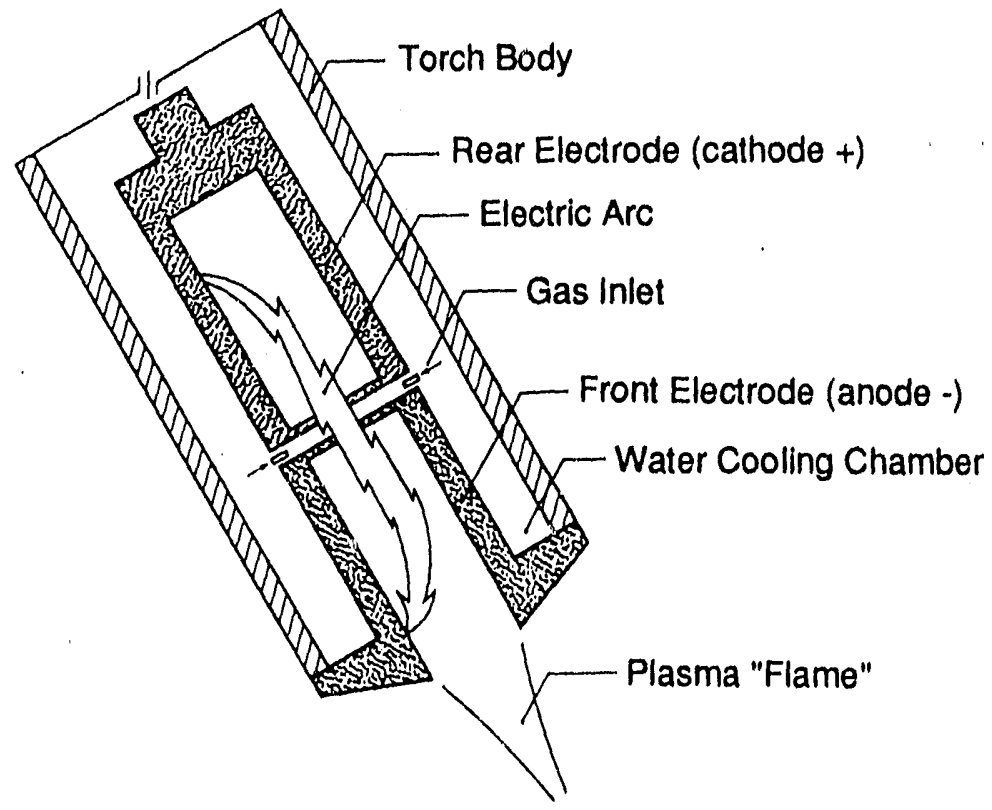

FIGURE 6 Schematic of the Plasma Torch. Source: Adapted from Dube and Dube (1990) 
TABLE 5 Summary of the Results of the Plasma Plbt-Plant Operation

\begin{tabular}{|c|c|c|c|c|}
\hline $\begin{array}{c}\text { Type } \\
\text { of Dross }\end{array}$ & $\begin{array}{l}\text { Quantity } \\
\text { (t) }\end{array}$ & $\begin{array}{l}\text { Plasma } \\
\text { Gas }\end{array}$ & $\begin{array}{c}A l \\
\text { Recovery } \\
(\%)\end{array}$ & $\begin{array}{c}\text { Process } \\
\text { Efticiency } \\
(\%)\end{array}$ \\
\hline \multirow{5}{*}{$\begin{array}{l}\text { Smelter } \\
\text { (Mg-free) } \\
\text { Smelter } \\
\text { (low Mg) } \\
\text { Remelt } \\
\text { (low Mg) } \\
\text { Remelt } \\
\text { (high Mg) } \\
\text { Recyoling } \\
\text { (foundry) } \\
\text { Others } \\
\text { (mixed alloys) } \\
\text { Total }\end{array}$} & $\begin{array}{r}50 \\
30 \\
110\end{array}$ & $\begin{array}{l}\text { Alr } \\
\mathrm{N}_{2} \\
\text { Air }\end{array}$ & $\begin{array}{l}64 \pm 5 \\
65 \pm 4 \\
45 \pm 4\end{array}$ & $\begin{array}{l}92 \pm 3 \\
93 \pm 3 \\
85 \pm 3\end{array}$ \\
\hline & 40 & Air & $57 \pm 3$ & $84 \pm 5$ \\
\hline & $\begin{array}{l}10 \\
10 \\
20\end{array}$ & $\begin{array}{l}\text { Air } \\
\mathrm{N}_{2} \\
\text { Air }\end{array}$ & $\begin{array}{l}41 \pm 4 \\
40 \pm 4 \\
30 \pm 3\end{array}$ & $\begin{array}{l}80 \pm 5 \\
81 \pm 5 \\
83 \pm 6\end{array}$ \\
\hline & 136 & Air or $\mathrm{N}_{2}$ & $9-66$ & $78-91$ \\
\hline & 406 & & & \\
\hline
\end{tabular}

Source: Adapted from Dube and Dube (1990)

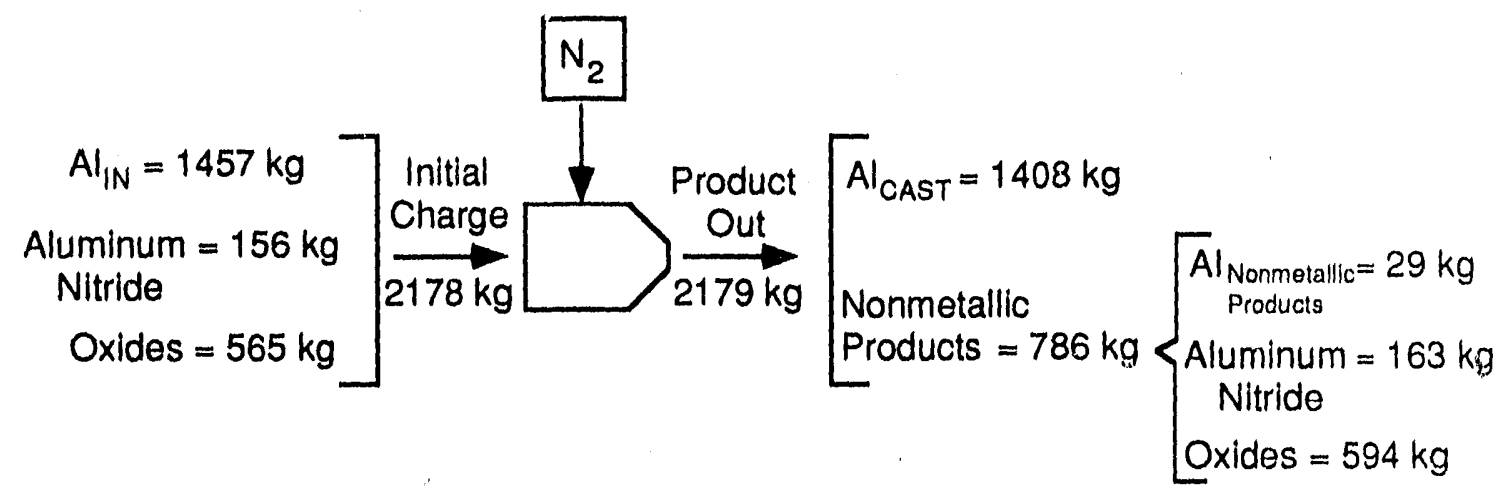

$\%$ Recovery $=\frac{\left.A\right|_{\text {CAST }}}{\text { Initia! Charge }}=\frac{1408}{2178}=64.6 \%$

Process Efficiency $=\frac{A l_{\text {CAST }}}{A l_{I N}}=\frac{1408}{1457}=96.6 \%$

FIGURE 7 Typical Mass Balance for. Nitrogen Plasma (magnesium-free smelter dross). Source: Adapted from Dube and Dube (1990) 


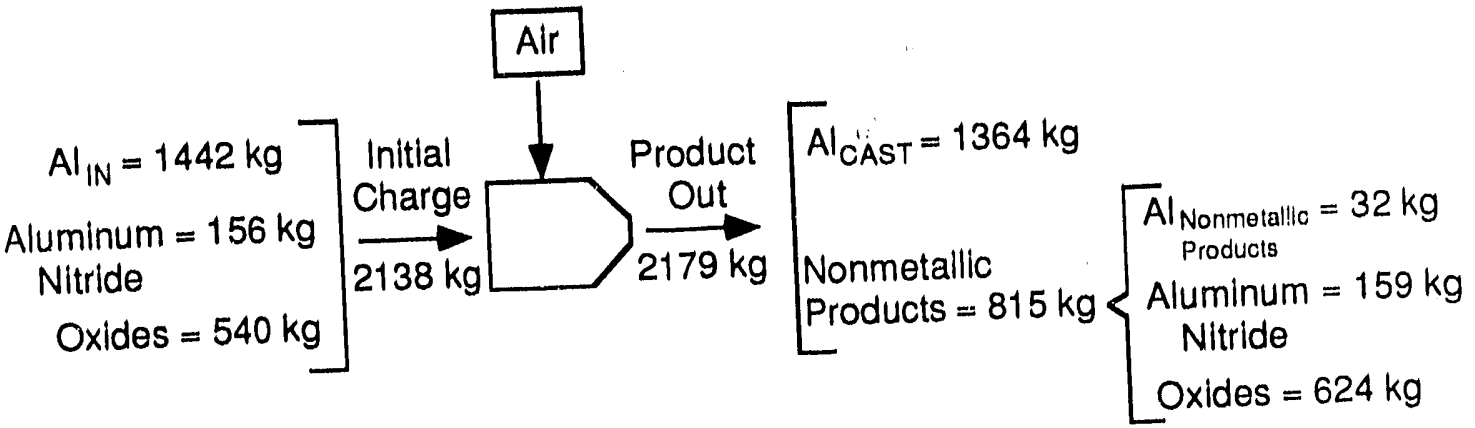

$$
\begin{aligned}
& \% \text { Recovery }=\frac{A l_{\text {CAST }}}{\text { Initial Charge }}=\frac{1364}{2138}=63.8 \% \\
& \text { Process Efficiency }=\frac{A l_{\text {CAST }}}{A l_{\mathbb{N}}}=\frac{1364}{1442}=94.5 \%
\end{aligned}
$$

FIGURE 8 Typical Mass Balance for Air Plasma (magnesium-free smelter dross). Source: Adapted from Dube and Dube (1990)

The plasma dross-treatment process is an innovative and potentially cost-effective approach for the recovery of aluminum from drosses of the primary aluminum industry. ${ }^{*}$ The advantage of this process is that it eliminates the salt flux requirements for recovering the aluminum from dross. Therefore, salt-free by-products can be generated, but only if the dross charged into the furriace does not contain any salt (as is typically in some primary aluminum industry drosses). If the processed dross contains salt flux (as in black dross), the salt will remain in the residual waste and will need further processing in order to recover its constituents and recycle the salt.

The preliminary tests and evaluations that have been conducted by Alcan on the technical and efficiency performances of this process are promising, but its long-term economic performance has yet to be proven. The capital and operating costs of this system have not been documented, although the manufacturer claims that the technology will be competitive with conventional aluminum-recovery systems.

Alcan is building a $15 \times 10^{3}-\mathrm{t} / \mathrm{yr}$ plasma dross-treatment plant in Canada. This commercial-scale facility will provide reliable data that can be used to evaluate (1) the applicability of this process and (2) its technical and cost-effectiveness for addressing the waste-minimization and disposal issues facing the secondary and primary aluminum industries.

*Black dross produced by the secondary aluminum industry is much more corrosive, and it is not clear from the available test data whether the plasma dross-treatment process would be suitable for recovering aluminum from black dross. 


\section{Review and Evaluation of Innovative Concepts for Recovering Salt from Dross and Salt Cake}

As discussed earlier, several commercial processes are being developed in which water is used for the leaching of chlorides from aluminum salt cake, including processes by Engitech Impianti Ltd. (Italy) and American Recovery Technology Systems, Inc. These processes rely on the evaporation of water to concentrate and recover the salts after they are leached. With the use of a single-stage evaporator, a minimum of about $0.64 \mathrm{kWh}$ of energy per kilogram of water processed is required in order to evaporate the water. The use of multiple-effect evaporators could reduce this energy requirement by about $50 \%$. In its literature, Licon, Inc., which is located in Pensacola, Florida, stated that similar solutions can be concentrated by using about 50-100 Btu per pound $(0.032-0.065 \mathrm{kWh} / \mathrm{kg})$ of water removed. Licon's process uses vapor compression to recycle the latent heat and operates at reduced pressures in the range of 20-26 in. of mercury. The estimated cost of the equipment is about $\$ 500,000-\$ 750,000$ for a system that can treat about 500-1000 gal/h.

The evaporated water in evaporation processes is generally lost when it is released to the environment. It could, however, be condensed and reused, but the process is not economical. The evaporation process also releases gaseous impurities that evolve during boiling. Therefore: a more efficient and cost-effective process to separate the salts from the water is desirable. As part of our effort, we evaluated the following concepts in search of a more efficient and economical method:

1. Freeze crystallization,

2. Solvent/antisolvent extraction,

3. Common-ion effect,

4. High-pressure/high-temperature process, and

5. Capillary-effect systems.

\subsection{Freeze Crystallization}

Freeze crystallization involves cooling the solution beyond its saturation point, at which the salts begin to crystallize and precipitate. Cooling may be continued until pure ice crystals start to form and rise to the surface, resulting in the precipitation of more salts. The process may be operated at reduced pressures (below the triple point of water) where water evaporates and ice forms simultaneously. The solution can be cooled via indirect or direct heat-exchange methods. In indirect cooling, the solution does not come in contact with the refrigerant, while in direct cooling, a refrigerant is added directly to the solution. Capellini (1980) reported that the upper solidsconcentration level is limited by viscosity constraints, and that the highest feed stream concentrations investigated are on the order of $10 \%$ total dissolved solids. He also reported that 
solutions containing as little as $30 \mathrm{ppm}$ of total dissolved solids can be treated by this method, thereby yielding $99.9 \%$ recovery of the dissolved solids.

A recent article by Roy (1990) described the direct cooling method. The author reported that the process is cost-effective for wastewater from any industry with recoverable by-products worth more than one cent per gallon. According to a representative of Freeze Technologies Corp. in Raleigh, North Carolina, this method will separate the salt-cake salts, produce pure water, and may enable the recovery of magnesium chloride from the solution in marketable purity. The recovery of magnesium chloride is also favored because one of the reasons for using the salt flux in the first place is to capture and remove magnesium from the aluminum in the form of magnesium chloride. The estimated installed equipment cost for a unit having a capacity of $10^{7} \mathrm{Btu} / \mathrm{h}$ ( $3500 \mathrm{gal} / \mathrm{h}$ ) is about $\$ 2,000,000$, excluding the cost of scraped surfaces (Heist 1979).

The applicability of this process to water/salt solutions generated from the processing of aluminum salt cake was evaluated. On the basis of the evaluation, the following conclusions were drawn:

1. The dominant salts in the cake are sodium and potassium chlorides. Magnesium chloride is also present, but in smaller quantities $(<3 \%)$. The individual solubilities of these salts in water at different temperatures are shown in Fig. 9. The data in the figure indicate that the higher the temperature at which the salt-dissolution process is carried out, the less water required per unit mass of salt dissolved (and thus less water will have to be frozen). This phenomenon is particularly true in the case of potassium chloride. Experiments conducted at Argonne National Laboratory (ANL) in which actual salt-cake materials were used indicated that at room temperature $\left(-20^{\circ} \mathrm{C}\right)$, the solubility of the derived salt mixture is about $31.4 \mathrm{~g} / 100 \mathrm{~g}$ of saturated solution (about $45.8 \mathrm{~g}$ of salts/100 $\mathrm{g}$ of water). Experiments done at $\mathrm{ANL}$ in wilich a $50 / 50$ mixture of potassium and sodium chlorides at various temperatures $\left(30-90^{\circ} \mathrm{C}\right.$ range) was used yielded comparable results, as shown in Fig. 10.

2. Although considerably less energy is expended when freezing water than when boiling water, the energy used in the cooling process is generally electric, while heating can be achieved with less-expensive means. Furthermore, the cost of cooling equipment is generally higher than the cost of the heating equipment. Therefore, the freeze-drying process is generally more expensive to apply than the evaporation process, for which energy costs are low.

3. At $\$ 100 /$ ton for salts, the value of the recovered salts from the salt cake will be about $\$ 0.15 / \mathrm{gal}$ of water processed when the dissolution process takes place at room temperature. Heist (1979) estimated that the cost of the treatment would be about $8-13 c / \mathrm{gal}$. 


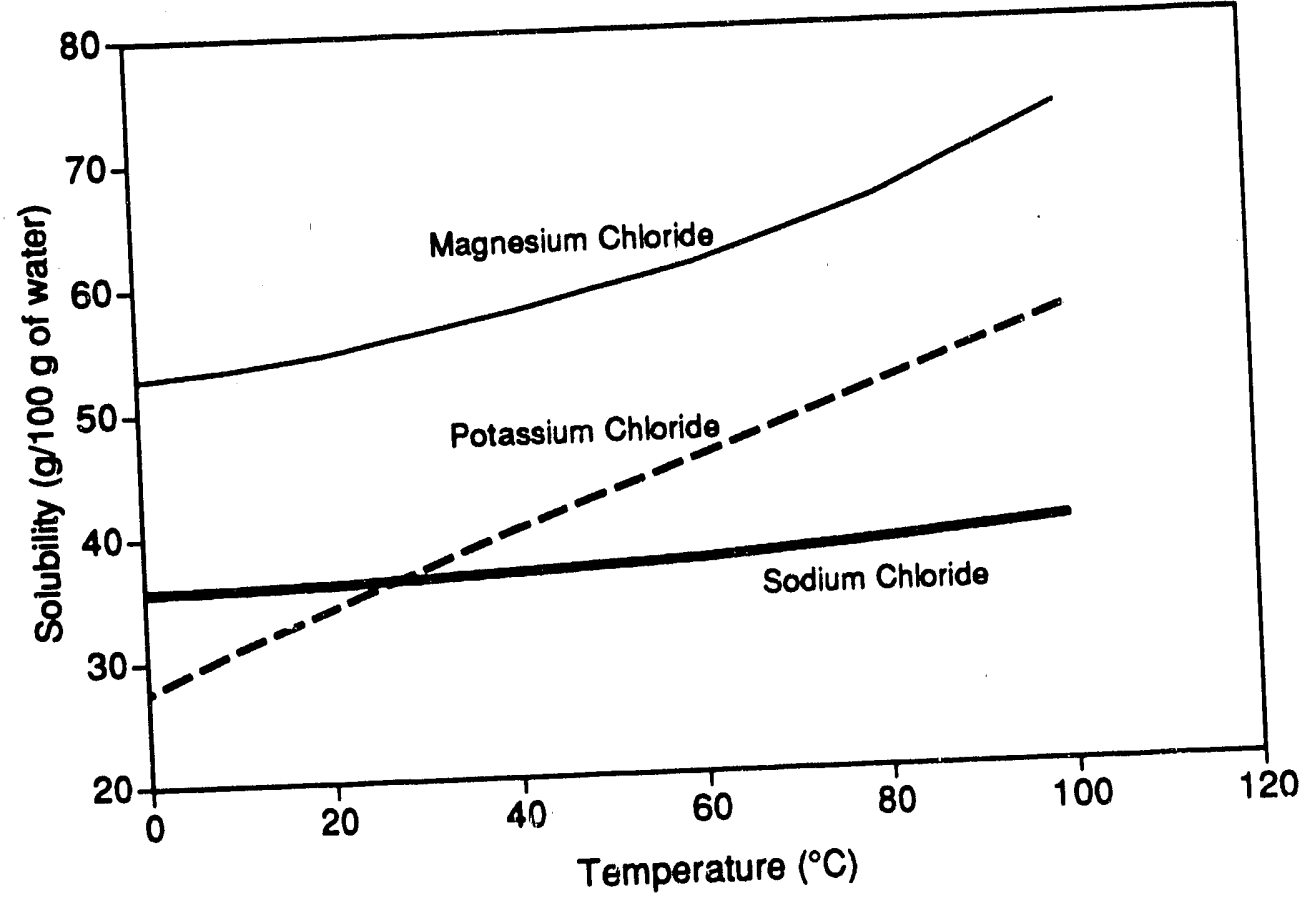

FIGURE 9 Solubility of Salt-Cake Salts in Water. Source: Data from Linke (1965)

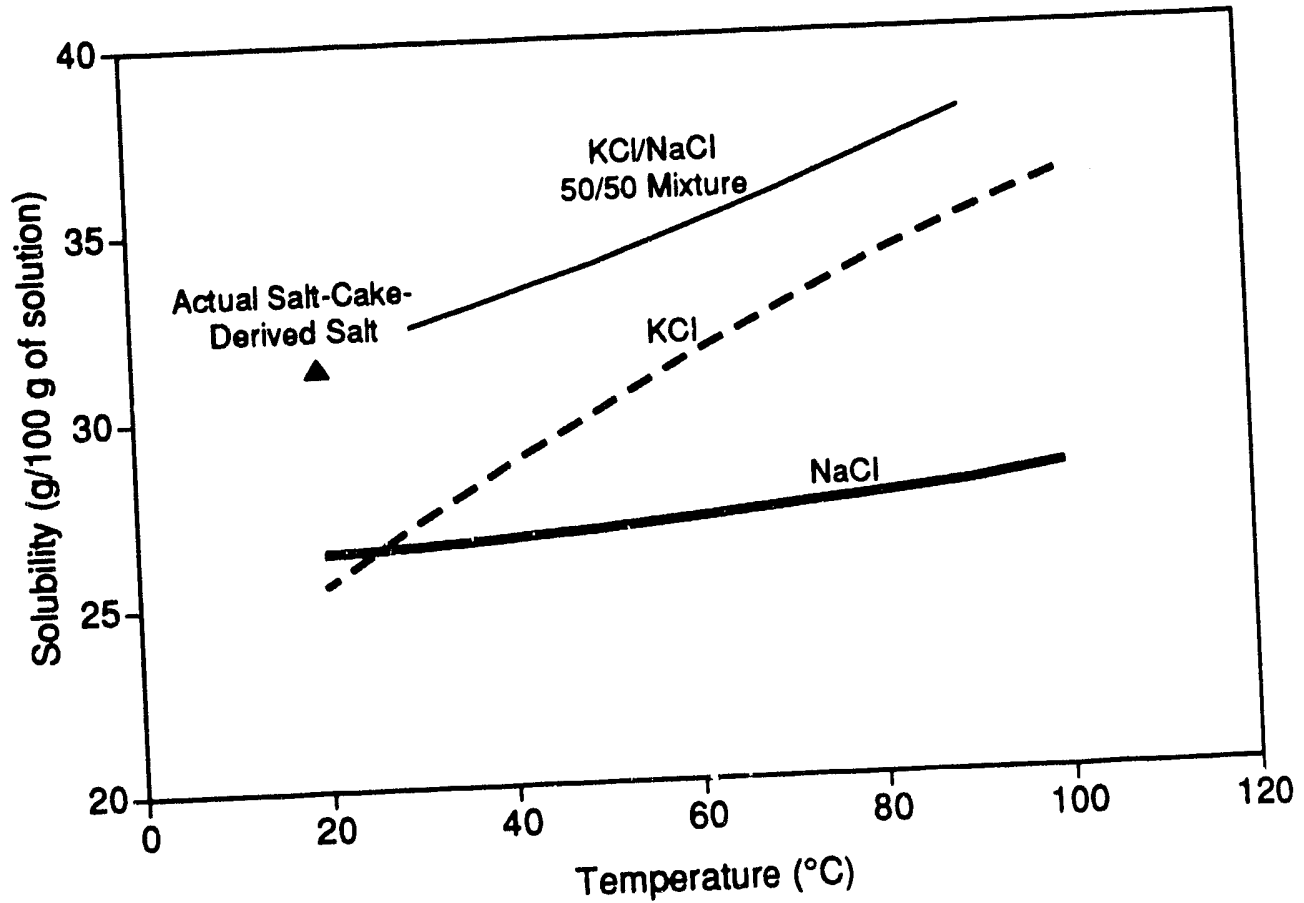

FIGURE 10 Comparison of the Solubility of Different Salts and Sali Mixtures in Water 


\subsection{Solvent/Antisolvent Extraction}

Precipitation of a solute from a solvent by the use of another solvent is a well-known technique that is widely practiced in the chemical and petrochemical industries. We experimented with this technique to separate the salts from water. In the laboratory, the precipitation of salts from a saiurated salt-cake solution, by means of water-miscible organic solvents, was tested by using several highly water-soluble organic solvents (acetone, isopropyl alcohol, ethyl methyl ketone, methyl alcohol, tetrahydrofuran, and dioxane). The inorganic salts commonly found in salt cake have negligible solubility in these organic solvents. Because of their high affinity for water and relative insensitivity to the salts, these solvents can displace the salts in solution, thereby causing the salts to precipitate. When a large amount of excess solvent is added, virtually all of the salts can be precipitated, leaving behind a mixture of water and the solvent with little salt in the mixture. After the precipitate is filtered, the liquid mixture can be separated by distillation, and the solvent and water can be recovered by distillation of the solvent for reuse. The latent heat of vaporization of organic solvents is considerably lower than that of water, as are their boiling points. Therefore, lower-grade heat can be used in the distillation process.

Experiments were conducted with a saturated salt-cake solution prepared by using salts recovered from a commercial sample of salt-cake slag. The salt content of the solution was found to be $31.52 \%$ by weight, and it contained about $45 \%$ potassium chloride and $55 \%$ sodium chloride. Various quantities of solvents were added to $50-\mathrm{mL}$ samples of salt-saturated water solution (the saturated water contained about $19.2 \mathrm{~g}$ of salts). As a result, various amounts of salts precipitated from solution. After about an hour, the prucipitates were filtered, dried, and weighed. In the samples where excess solvent was added, two liquid phases separated, because the solubility of the water-miscible solvents decreased in the salt solution (as compared with salt-free water). The excess layer can be decanted and reused without additional treatment because of its lack of contamination. The results obtained with different solvents are discussed below.

Preliminary tests of mutual compatibility eliminated methyl alcohol, methyl ethyl ketone, and tetrahydrofuran from further consideration. Methyl alcohol, because it was compatible with the salt solution, caused negligible salt precipitation. The other two solvents showed negligible solubility in the salt solution. Warranting further consideration were acetone, isopropyl alcohol, and dioxane. The results obtained with these water-miscible solvents are summarized in Table 6 and Fig. 11. As expected, the solubility of the organic water-miscible solvents in the salt solution was observed to significantly decrease (as compared with salt-free water), so that a separate upper phase, rich in organic water-miscible solvents, was formed. We investigated whether this upper phase could be used after decanting to desalinate fresh saturated solutions. In the case of acetone, $30 \mathrm{~mL}$ of the supernatant liquor was added to $50 \mathrm{~mL}$ of fresh saturated solution. This procedure resulted in the precipitation of $1.65 \mathrm{~g}$ of salt $(8.6 \%)$, which is about half of what was precipitated when fresh acetone was used. Similarly, when $30 \mathrm{~mL}$ of isopropyl alcohol was added to $50 \mathrm{~mL}$ of fresh saturated solution, it precipitated about $1.14 \mathrm{~g}$ of salt $(5.9 \%)$, which is, again, about half of what was precipitated when fresh isopropyl alcohol was used. Because of dioxane's cost, suspected carcinogenicity, and tendency toward peroxide formation, its consideration for this technology is much less attractive. 


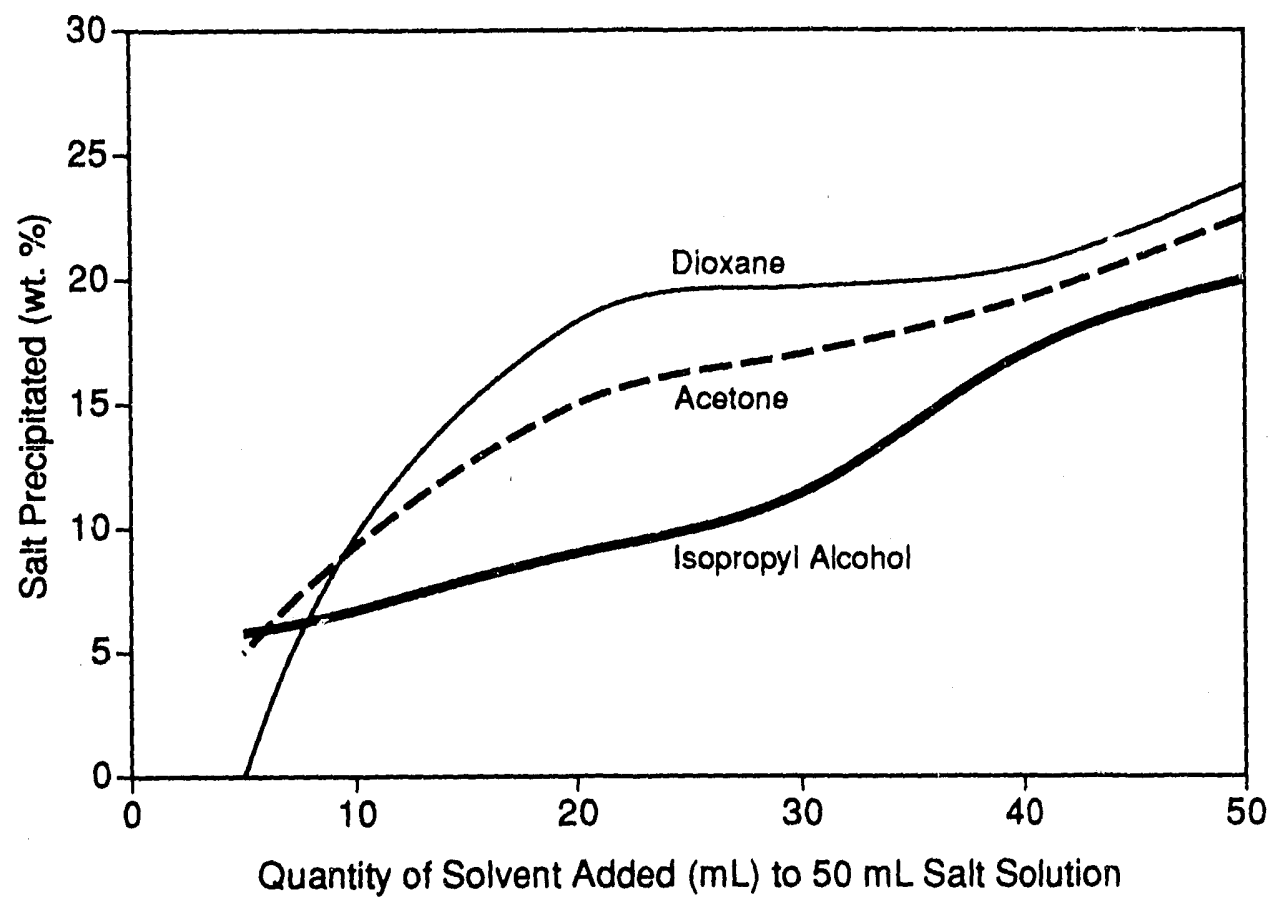

FIGURE 11 Effect of Various Water-Miscible Solvents on Salt Precipitation

The data in Table 6 and Fig. 11 indicate that on the basis of the amount of salt precipitated per milliliter of solvent added, dioxane appears to be the most effective solvent, followed by acetone. However, dioxane (in addition to its other negative considerations) forms an azeotrope with water, making it more difficult to separate. Furthermore, in both cases, the energy required to regenerate the solvent is more than the energy required to separate the same amount of salt by boiling the water. For example, to boil off $1 \mathrm{lb}$ of acetone, about $22 \%$ of the energy needed to boil $1 \mathrm{lb}$ of water is required, but it will precipitate about $20 \%$ of the salt that can be precipitated by boiling the water. Thus, larger and more expensive evaporation equipment will be needed.

We also evaluated a hybrid system (Fig. 12) in which water is boiled off in the first section, and acetone is used in the second section. The steam generated in the first section (leaving a multiple-effect evaporator at approximately one atmosphere) is used to regenerate the solvent in the second section. This process takes advantage of acetone's lower boiling temperature. The solvent section can be sized to match the capacity of the effluent steam from the multiple-effect evaporator, and thus it could be operated energy-free. Typically, the solvent section should be able to handle about $25 \%$ of the total saturated water solution, which corresponds to a $25 \%$ reduction in the energy requirement of the process employed to separate the water from the salts. 
TABLE 6 Results oi Salt Precipitation Tests Conducted with Water-Miscible Solvents ${ }^{a}$

\begin{tabular}{cccc}
\hline & \multicolumn{3}{c}{$\begin{array}{c}\text { Mass Percent of Salts } \\
\text { Recovered (by solvent) }\end{array}$} \\
\cline { 2 - 4 } $\begin{array}{c}\text { Volume of } \\
\text { Solvent Added } \\
\text { (mL) }\end{array}$ & $\begin{array}{c}\text { Isopropyl } \\
\text { Acetone }\end{array}$ & $\begin{array}{c}\text { Isopropyl } \\
\text { Alcohol }\end{array}$ & $\begin{array}{c}\text { Isopropyl } \\
\text { Dioxane }\end{array}$ \\
\hline & & & \\
5 & 5.0 & 5.8 & 0 \\
10 & 9.3 & 6.7 & 9.7 \\
20 & 15.0 & 9.0 & 18.3 \\
30 & 17.0 & 11.4 & 19.7 \\
40 & 19.2 & 17.0 & 20.5 \\
50 & 22.5 & 20.0 & 23.8 \\
100 & 32.9 & 33.1 & 31.6 \\
\hline
\end{tabular}

avolume of saturated water solution $=50 \mathrm{~mL}$.

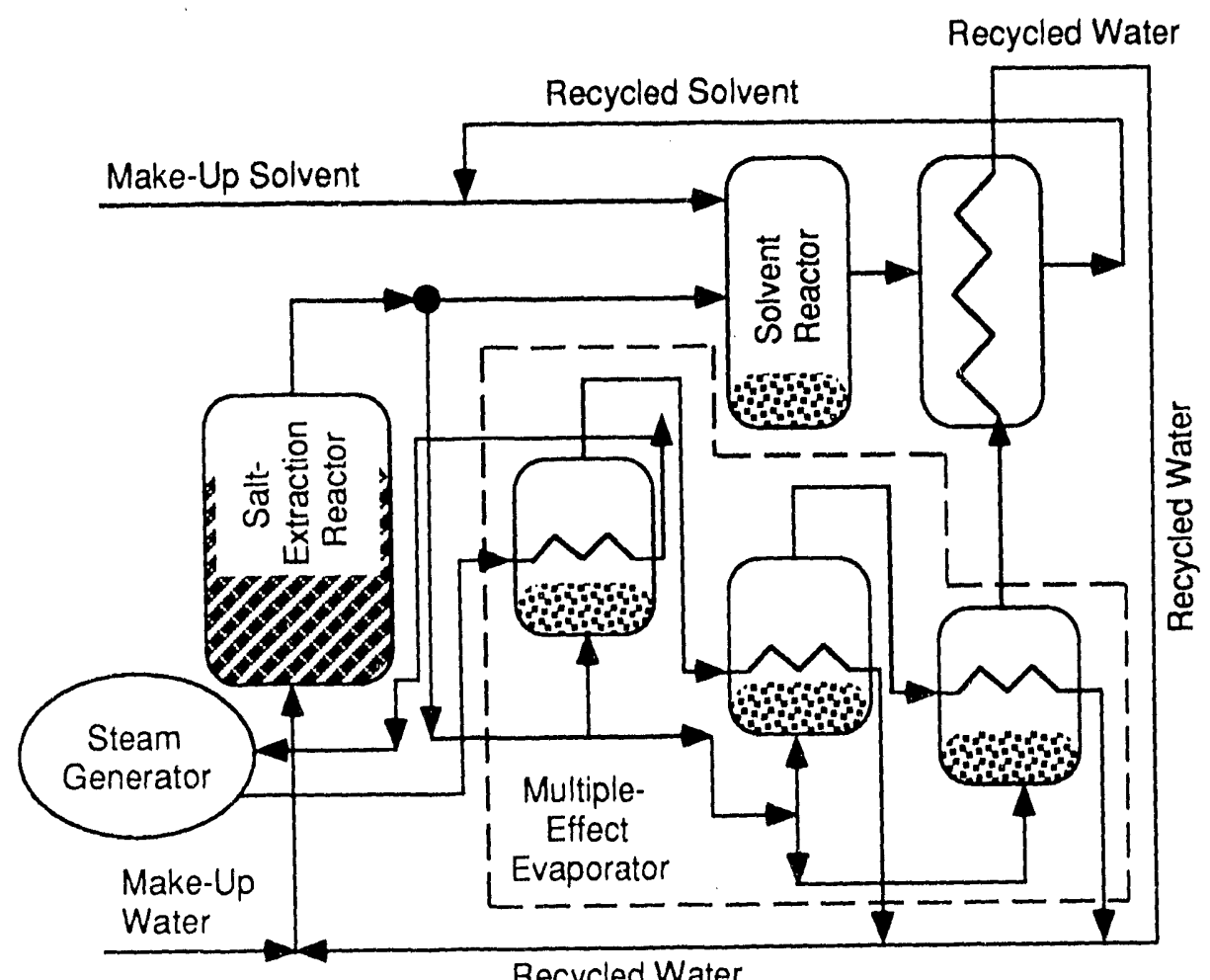

FIGURE 12 Diagram of the Hybrid Evaporation/Solvent-Precipitation System 


\subsection{Common-ion Effect}

We conducted a preliminar study of the concept of precipitating salt-cake salts from a saturated solution by the addition of compounds containing chloride ions. Two sources of chloride ions were evaluated: hydrochloric acid and lithium chloride. The results are discussed below.

\subsubsection{Addition of Hydrochloric Acid}

Commercial hydrochloric acid contains about $38 \%$ by weight hydrogen chloride and $62 \%$ water. Hydrogen chloride, with chloride ion as the common ion, is the active ingredient in precipitating the salt. When $50 \mathrm{~mL}$ of concentrated hydrochloric acid was added to $50 \mathrm{~mL}$ of saturated salt solution, $55.2 \%(10.6 \mathrm{~g})$ of its salt content was precipitated. This quantity of salt precipitation was significantly greater than that yielded by water-miscible solvent precipitation. Clearly, it would be more efficient to bubble $100 \%$ hydrogen chloride gas directly into the salt solution.

The residual acidified solution can be filtered in order to remove the precipitated salts and reconcentrated by boiling or freeze crystallization, which would remove some of the solution's water content. A concentration of about $38 \%$ can be attained by such methods. Further concentration would require more elaborate techniques because the acid/water azeotrope would need to be broken. Therefore, we do not expect this technique to offer any energy or cost savings over the simple removal of water by boiling or freezing.

\subsubsection{Addition of Lithium Chloride}

Lithium chloride was considered because of its high solubility in water and the strong and extensive hydration sphere for the small $\mathrm{Li}^{+}$ion, which might help "squeeze out" the salts from the total aqueous environment. The significant disadvantages of this approach include the following: (1) the high cost of lithium chloride, (2) the possible coprecipitation of lithium chloride with the potassium and sodium salts (thereby contaminating the recovered product), and (3) recovery and reuse problems associated with water and lithium chloride.

Fifty milliliters of saturated lithium chloride solution ( $40 \%$ by weight) was added to $50 \mathrm{~mL}$ of saturated salt solution. This procedure resulted in the precipitation of $11.2 \mathrm{~g}$ of salt $(58.2 \%)$. Although lithium chloride performed slightly better than hydrochloric acid, we do not believe its performance is significantly better in light of the disadvantages described above. Therefore, this approach was not investigated further.

\subsection{High-Temperature/High-Pressure Process}

We conceived a closed-system process that involves leaching the salts at elevated temperatures using pressurized water. This process is described below. 


\subsubsection{Process Concept}

The proposed process exploits the dependence of salt solubility on temperature, as shown in Fig. 13. The process consists of leaching the salts at elevated temperatures by using compressed liquid water and effecting the crystallization of the salts from the water by cooling. The water is cooled by preheating the salt-deficient stream that is used for leaching the salts. The leaching process can be carried out at subcritical or super-critical conditions. Figure 14 is a diagram of the process. The approximate material and energy data shown in Fig. 14 are for leaching at $315^{\circ} \mathrm{C}$ and are intended for illustration only. At this condition, the process will consume about $8 \%$ of the energy required by the evaporation process, which uses a multiple-effect evaporator. The process requires additional equipment (such as a chiller, heat exchangers, and a centrifuge) or an equivalent system for solid/liquid separation. As stated earlier, the system consumes electricity, which is a more expensive fuel than a regular fossil fuel.

The concept of leaching the salts at elevated temperatures can be integrated with more efficient separation methods, such as the Licon and freeze-crystallization processes. The large temperature gradient in the liquid/liquid heat exchanger enables the efficient recovery of a substantial portion of the heat in the salt-loaded stream. Another advantage of this process is that it conserves water. Except for the venting of gases generated during the leaching process, which will include small amounts of steam, the process is closed, and thus the water is recycled.

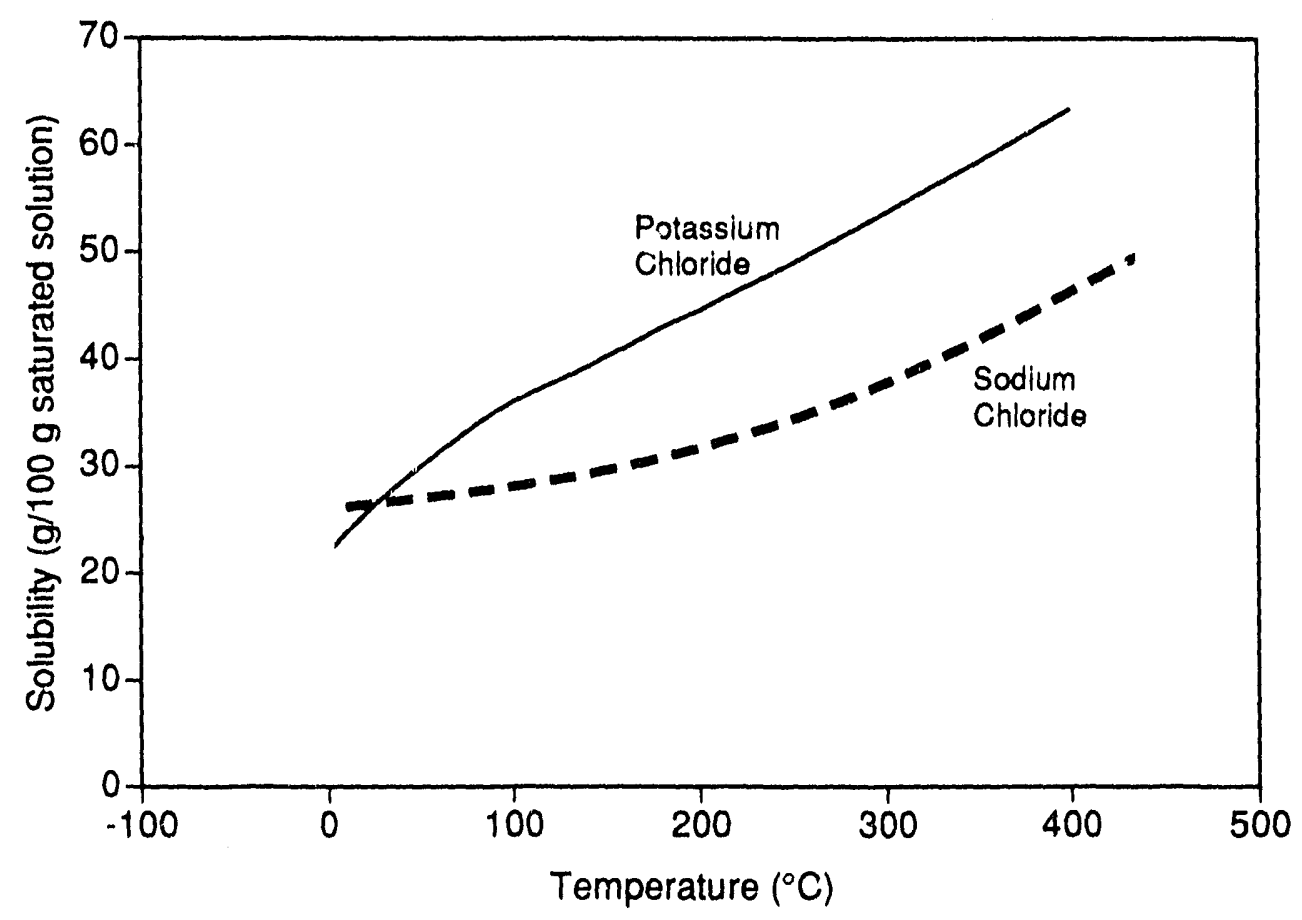

FIGURE 13 High-Temperature Solubility Data of Sodium and Potassium. Source: Data from Linke (1965) 


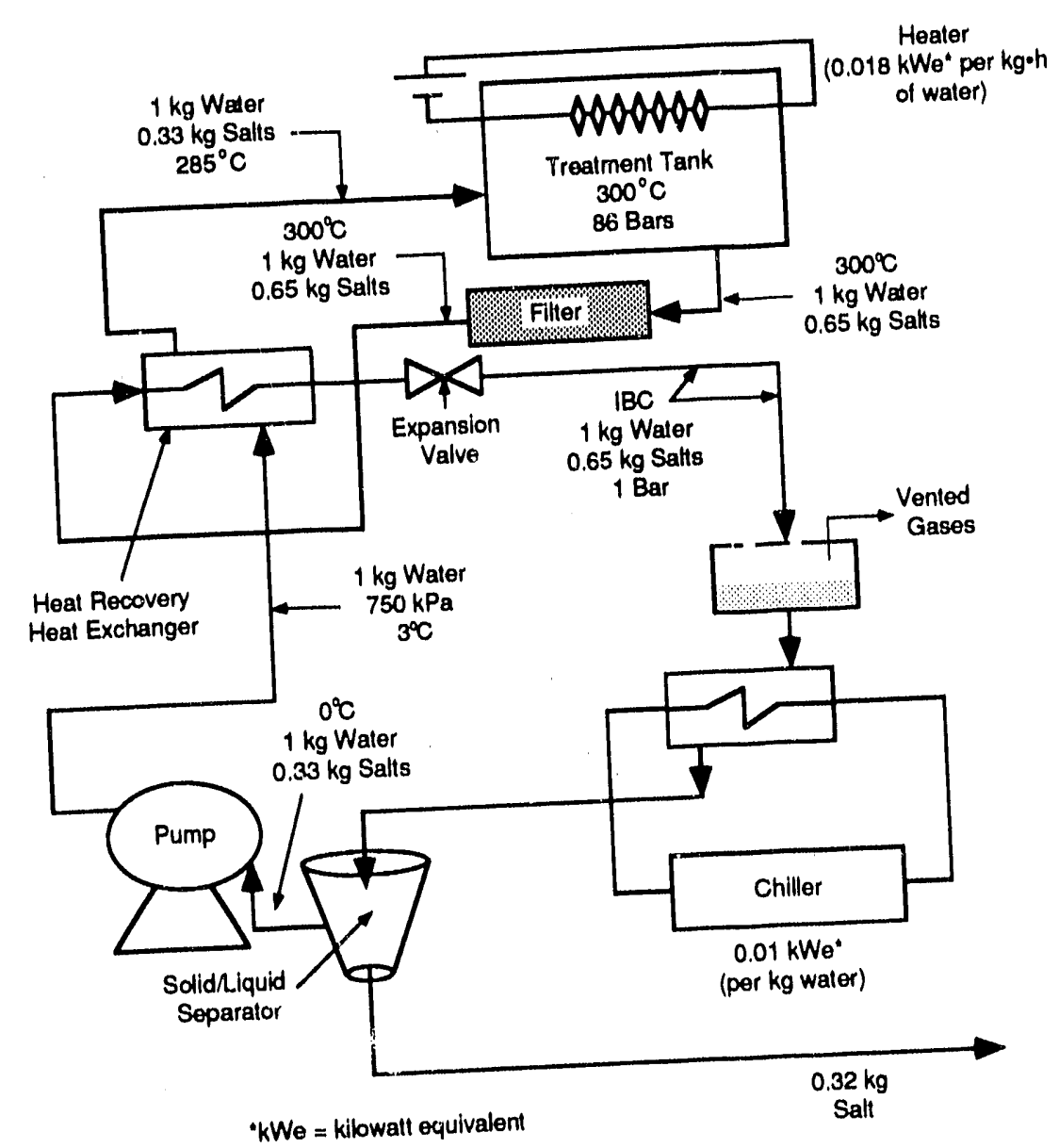

FIGURE 14 Diagram of the High-Temperature, High-Pressure Process

\subsubsection{Advantages of Operating with High-Temperature, Compressed- Llquild Water}

Figure 13 shows the solubility of sodium and potassium chlorides in liquid water at different temperatures. If the temperature is increased from about $20^{\circ} \mathrm{C}$ to $300^{\circ} \mathrm{C}$, then the solubilities of the sodium and potassium chlorides in liquid water are increased by about $40 \%$ and $110 \%$, respectively. Therefore, more salts can be leached rapidly (and at higher in aluminum by each kilogram of water. For a 50/50 mixture, which is the mixture encounter in aluminum salt cake, an overall increase of over $75 \%$ is expected. This increase is consistent we pumping of water values for the mixture in the range of $20-100^{\circ} \mathrm{C}$ shown the use of compressed, hot liquid water can requires very little energy compare conserve substantial quantities of enould be considered. Reaction of the hot water with aluminum increased temperatures, how major problem because about $3 \%$ of the salt cake consists of aluminum. is not expected to be a major pe aluminum oxide at the elevated temperatures would be an added The possibility of hydrating the aluminume proceed at a practical rate under operating conditions. beneficial effect, but only if it were to proced to produce aluminum, and this procedure would Hydrated aluminum oxides could be used to produce alu 
eliminate the problem of salt cake because every component of it would then be recycled. This issue is discussed in more detail in Sec. 5.1 of this report.

\subsubsection{Conceptual Design}

In Fig. 14, approximate material and energy data are shown for the case when the saltdissolution process is carried out at $300^{\circ} \mathrm{C}$. The data indicate that less than $140 \mathrm{Btu} / \mathrm{lb}$ of salt recovered will be required. If the process were conducted at room temperature and the water separated by using a triple-effect evaporator, the energy requirement of the process would be about $10^{3}$ Btu per pound of salt recovered. As was discussed in Sec. 4.4.2, leaching of sodium and potassium chlorides from aluminum salt cake at elevated temperatures is an efficient process for separating the salts from aluminum and aluminum oxides that are present in the salt cake. Carrying out the leaching process at $300-400^{\circ} \mathrm{C}$ requires about $40-50 \%$ less water than what is required at room temperature. The recovery of heat from the hot salt-loaded stream by the water that is returned to the treatment reactor efficiently separates the salts from the water without the loss of the water. This procedure is potentially capable of reducing the energy requirements of the process by as much as $80-90 \%$ over evaporation in a multiple-effect evaporator.

\subsection{Capillary-Effect Systems}

While conducting various experiments on separating dissolved salts from aqueous solutions, we used smooth, glass beakers that were less than half-filled with salt solutions. The beakers were left in the hood for some period; as expected, water evaporated from the solution, leaving behind the salts. We also observed the following:

1. Although the beakers were initially less than half-filled with salt solutions, the entire internal surfaces of the beakers were covered with salt crystals. The thickness of the salt layer on the sides of the beakers continued to build up as long as an aqueous solution remained in the beakers.

2. The thickness of the salt-crystal layer in each beaker appeared uniform, except on the bottom of the beakers where it was thicker. The thickness of the salt layer appeared to be a function of the salt concentration in solution.

3. One could easily collect the salt crystals by scraping the sides of the beaker. The inner crystals appeared more strongly attached than the outer ones.

On the basis of these observations, a concept was conceived that involves the use of capillaryeffect and diffusion-enhanced dryers and heat-transfer equipment.

Porous or semiporous fibers can be used to facilitate the diffusion of water and salt ions and the eventual rapid drying of the salts. The salts dry rapidly because of the increased surface area for heat and mass transfer. The increased surface area can be designed to more than compensate for the lack of a large temperarure gradient, which is normally the driving force in heat- 
exchange processes (such as drying operations). The mass-transfer process (water evaporation) can be further accelerated through the use of forced-convection techniques, such as blowing air over the diffusing front. Should waste heat be available, it can be used to further accelerate the rate of mass transfer.

As we observed, one can collect the dried salts by scraping the outer layers or by agitating the porous media; the dried salts can also be air-blown inro a collection vessel. Although the use of this method results in the loss of water, its operating cost should be very low. Because we have not performed quantitative experiments to study this concept, we cannot discuss its merits in detail.

Figure 15 is a diagram of a possible dryer or heat-exchanger design. Another possible design is a slowly rotating drum equipped with porous fins.

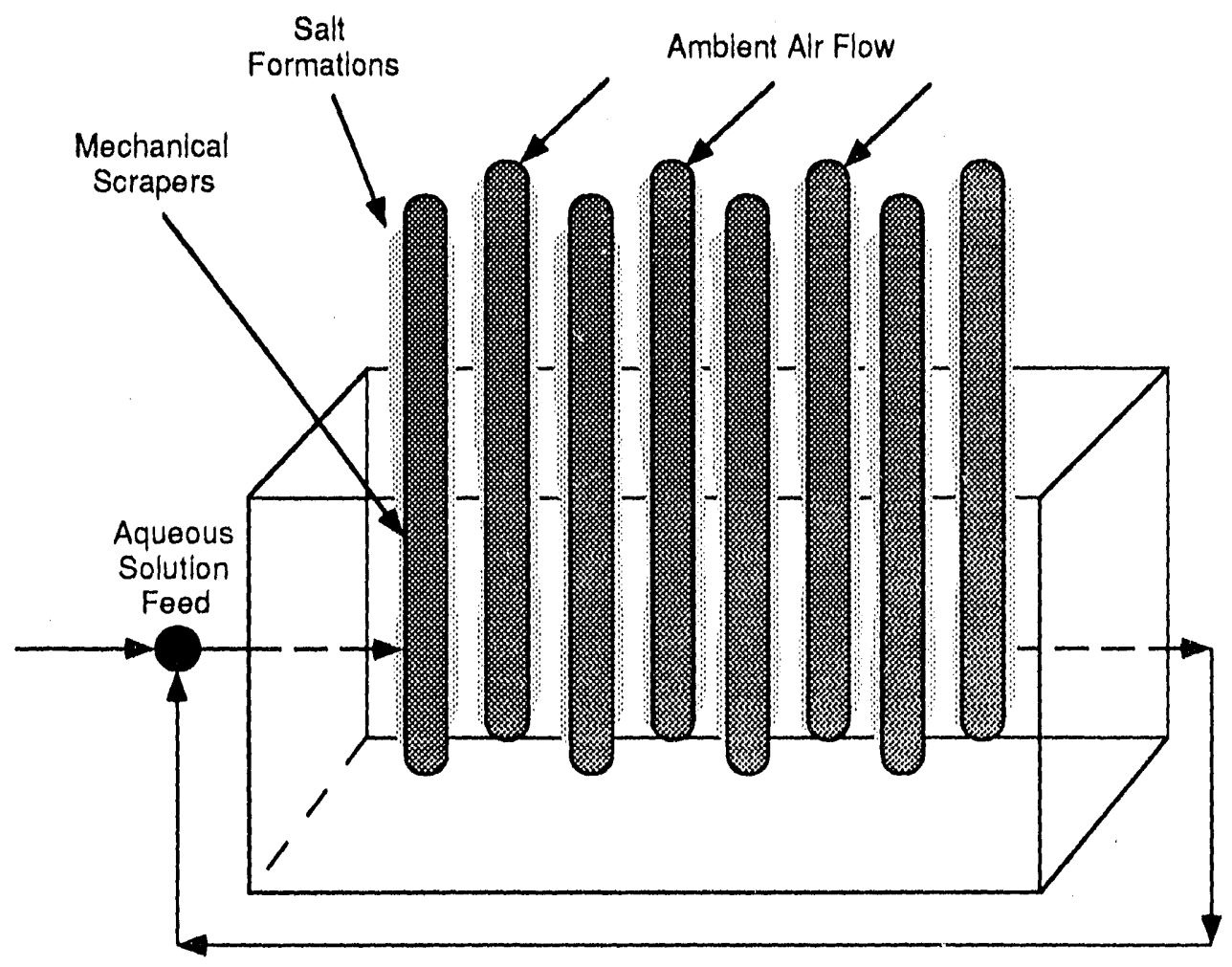

FIGURE 15 Conceptual Design of a Capillary-Effect/Diffusion-Enhanced Dryer 


\section{Approaches to the Use of Aluminum-Oxide Waste In the Secondary Aluminum Scrap-Metal- Reclamation Industry}

As noted in the preceding sections of this report, the ultimate disposal of aluminum oxide, $\mathrm{Al}_{2} \mathrm{O}_{3}$ (alumina), contaminated by salt and aluminum metal is a costly and debilitating environmental concern, the seriousness of which can only increase into the foreseeable future. The development of technology to turn waste alumina into a resource material for conversion into highvalue aluminum metal and/or other aluminum compounds would offer significant advantages. The refractory nature of that alumina and its contamination with other undesirable metallic elements (e.g., $\mathrm{Fe}, \mathrm{Cu}, \mathrm{Cd}, \mathrm{Pb}$, and $\mathrm{Sb}$ ) and minerals (silica, titania, and calcium and magnesium oxides) have, until now, limited serious investigations of possible approaches to reclaim value from that alumina.

Two compounds used for the conversion of waste alumina into higher-valued aluminum products are purified hydrated alumina and purified aluminum chloride.

\subsection{The Bayer Process}

\subsubsection{Current Technology for Processing Aluminum Metal*}

Bauxitic ores are the primary source of purified alumina used in the Hall-Heroult process for preparing aluminum metal by the electrolysis of alumina solutions in molten cryolite baths. The ores contain $45-j 5 \%$ aluminum oxide in its hydrated form, either as the trihydrate, $\mathrm{Al}(\mathrm{OH})_{3}$ (gibbsite), or as the monohydrate, $\mathrm{AlO}(\mathrm{OH})$ (boehmite).

Accompanying these hydrated aluminas are appreciable quantities of other mineral species, mainly iron oxides and aluminum silicates from which the alumina must be freed before the alumina can be used as a feedstock in the electrolysis bath. This separation is realized by the Bayer process, which involves the following steps: (1) dissolving the hydrated alumina in hot caustic solution; (2) separating the solution from the caustic insoluble oxides, hydroxides, and silicates; and (3) crystallizing pure alumina trihydrate with concomitant regeneration of reusable caustic. The recovered and purified alumina trihydrate (gibbsite), after washing, drying, and calcining, is suitable as a feedstock for the molten cryolite electrolysis bath.

\subsubsection{Sultability of Aluminum Oxide-Rich Dross and Salt-Cake Slag}

Bauxitic ores containing $45-55 \%$ hydrated aluminum oxides (Arkansas, Suriname, Jamaica) are sought after as the primary source of purified alumina for the production of aluminum

\footnotetext{
*Much of this discussion is based on information provided in Kirk-Othmer (1978a).
} 
metal; however, extremely rich (typically $60-70 \%$ ) aluminum-oxide product from the secondary aluminum scrap-metal-reclamation industry may also be an excellent primary source of alumina. The Bayer process - hot caustic digestion of the hydrated alumina components of bauxitic ores should be a readily adaptable technology for cleaning up and recovering the aluminum-oxide component of that waste stream.

According to Wefers and Bell (1972), a primary consideration in the suitability of the aluminum-oxide component in dross and salt-cake slag is the physical state of that oxide and its adaptability to hydration (i.e., its reactivity with water). Although anhydrous, dense, crystalline aluminas $\left(\mathrm{Al}_{2} \mathrm{O}_{3}\right)$ - such as corundum - are extremely refractory materials that do not react readily with water, finely divided, amorphous aluminas of high surface area (the form most likely present in dross and salt-cake slag) should react relatively easily with water to form hydrates.

If an operation for salt-cake digestion is part of a waste-reclamation process (e.g., the Engitec or Yerushalmi "closed-loop" process), conditions could be designed to favor that hydration reaction. The high-temperature water dissolution of salts (e.g., 250-300 $\mathrm{C}$ ) should permit more efficient digestion of salts (salt solubility increasing with temperature) and ensure the hydrothermal conversion of any anhydrous alumina to the more easily digestible alkali-soluble hydrates. Hightemperature water digestion will probably lead exclusively to the formation of boehmite, the monohydrated alumina (Wefers and Bell 1972).

Although the monohydrate boehmite is less desirable as a source material for the Bayer process (because it requires higher concentrations of caustic soda and higher processing temperatures than does the gibbsite trihydrate form), it is, nevertheless, a widely used raw material for alumina production.

\subsection{Purifled Aluminum Chloride}

Anhydrous aluminum chloride $\left(\mathrm{AlCl}_{3}\right)$ is a valuable, easily purified commodity chemical that is widely used as a catalyst in organic chemistry (Aluminum Recycling Association 1988). It is also used in the manufacture of aluminum and in the treatment of wastewater. Numerous applications can also be found in metallurgical, textile, and refractory processes and in pharmaceutical and cosmetic formulations.

\subsubsection{Commercial Production of Aluminum Chloride}

Kirk-Othmer (1978b) states: "For commercial production, chlorine reacts either with molten aluminum or with aluminum oxide, $\mathrm{Al}_{2} \mathrm{O}_{3}$, in an aluminous material [italics added for emphasis] such as clay or bauxite in the presence of a reductant. The latter may be carbon, carbon monoxide, phosgene or carbon tetrachloride. In the latter two cases, the gaseous reactant supplies both the carbon reductant and a portion of the chlorine for halogenation of the alumina." 
Moreover, "...the chlorination of aluminous materials in the production of aluminum chloride has been thoroughly investigated and has been in use for over 50 years." The chemical reaction involved is as follows:

$$
\mathrm{Al}_{2} \mathrm{O}_{3}+3 \mathrm{C}+3 \mathrm{Cl}_{2} \rightarrow 2 \mathrm{AlCl}_{3}+3 \mathrm{CO} \text {. }
$$

\subsubsection{Sultablilty of Aluminum Oxide-Rich Dross or Salt-Cake Slag}

Again, if bauxitic ores with $45-55 \%$ aluminum oxide (as hydrates) are already suitable as raw materials for the manufacture of aluminum chloride, waste streams rich in aluminum oxide $(60-70 \%)$ should serve equally well. Any residual aluminum metal in the waste stream will also convert to anhydrous aluminum chloride, as shown below:

$$
2 \mathrm{Al}+3 \mathrm{Cl}_{2} \rightarrow 2 \mathrm{AlCl}_{3}
$$

Because the reaction is run at moderately high temperatures $\left(650-750^{\circ} \mathrm{C}\right)$, other metal oxides converted to metal chlorides (e.g., $\mathrm{FeCl}_{3}, \mathrm{SiCl}_{4}, \mathrm{TiCl}_{4}$ ) would also distill. A second fractional distillation should permit the isolation of purified aluminum chloride (boiling point $=182^{\circ} \mathrm{C}$ ).

\subsection{Economics of Technologies for the Recycling of Black Dross and Salt Cake}

The cost of recycling reusable constituents in black dross and salt cake is very high if current recycling systems are used. The key factors influencing the economics of these systems are the landfill disposal cost, amount and value of recyclable materials, and the capital and operating costs. The process costs in each system may vary, but overall, the estimated process costs for a typical system are shown in Table 7. The concentration of salt and aluminum in the black dross has a direct impact in the process energy consumed and on the revenues generated from the sale of recyclable materials.

An analysis of the process costs and the concentration requirements of recyclable constituents in the black dross or salt cake indicates that if the aluminum concentration is greater than $10 \%$, the net revenues from the recovered aluminum and salts are sufficient to cover the operating and capital cost of the wet process. Capital charges (\$/ton) are estimated at a charge rate of $40 \%$ of the total capital cost. The two key constituents, aluminum and salt, are the major contributors to the potential revenues derived from the sale of the recyclable constituents. Figure 16 shows the economics of a typical wet-process system at various levels of aluminum concentrate.

As the concentration of aluminum decreases, revenues alone are insufficient to justify the costs of the process, and the economics become dependent on the credit for avoided landfill costs. The avoided landfill costs will have to be above $\$ 100 /$ ton to economically justify recycling black dross or salt cake with an aluminum concentration of $3 \%$. Figure 17 shows the break-even landfill costs at low concentrations of aluminum. 
TABLEE 7 Estimated Costs of Processing Black Dross and Salt Cake

\begin{tabular}{|c|c|c|c|c|}
\hline \multirow[b]{4}{*}{ Item } & \multicolumn{4}{|c|}{ Costs/Revenues (\$) } \\
\hline & \multirow{2}{*}{\multicolumn{2}{|c|}{$\begin{array}{c}\text { High-Salt Slag, } \\
20 \% \text { Al } \\
\text { Salt Content } \\
\end{array}$}} & \multirow{2}{*}{\multicolumn{2}{|c|}{$\begin{array}{c}\text { Salt Cake, } \\
3 \% \mathrm{Al} \\
\text { Salt Content }\end{array}$}} \\
\hline & & & & \\
\hline & $40 \%$ & $60 \%$ & $50 \%$ & $65 \%$ \\
\hline $\begin{array}{l}\text { Operating Costs } \\
\text { Manpower @ } \$ 17 / \mathrm{h} \\
\text { Electricity @ } \$ 0.06 / \mathrm{kWh} \\
\text { Water } \\
\text { Maintenance } \\
\text { Fuel @ } \$ 5 / 10^{6} \mathrm{Btu} \\
\text { Subtotal }\end{array}$ & $\begin{array}{r}10.00 \\
5.50 \\
0.50 \\
12.50 \\
6.60 \\
35.10\end{array}$ & $\begin{array}{r}10.00 \\
5.50 \\
0.50 \\
12.50 \\
9.90 \\
38.40\end{array}$ & $\begin{array}{r}10.00 \\
5.50 \\
0.50 \\
12.50 \\
8.25 \\
36.75\end{array}$ & $\begin{array}{r}10.00 \\
5.50 \\
0.50 \\
12.50 \\
10.75 \\
39.25\end{array}$ \\
\hline $\begin{array}{l}\text { Revenues } \\
\text { Al Concentration @ } \$ 0.45 / 1 \mathrm{~b} \\
\text { Exotherms @ } \$ 0.10 / 1 \mathrm{~b} \\
\text { Salt @ } \$ 0.05 / 1 \mathrm{~b} \\
\text { Subtotal }\end{array}$ & $\begin{array}{r}135.00 \\
40.00 \\
35.00 \\
210.00\end{array}$ & $\begin{array}{r}135.00 \\
40.00 \\
45.00 \\
220.00\end{array}$ & $\begin{array}{l}27.00 \\
0 \\
48.50 \\
75.50\end{array}$ & $\begin{array}{l}27.00 \\
0 \\
62.50 \\
89.50\end{array}$ \\
\hline Net & 174.90 & 181.60 & 38.75 & 50.25 \\
\hline Capital Cost (\$/Ion'yr) & 235.00 & 265.00 & 250.00 & 275.00 \\
\hline
\end{tabular}




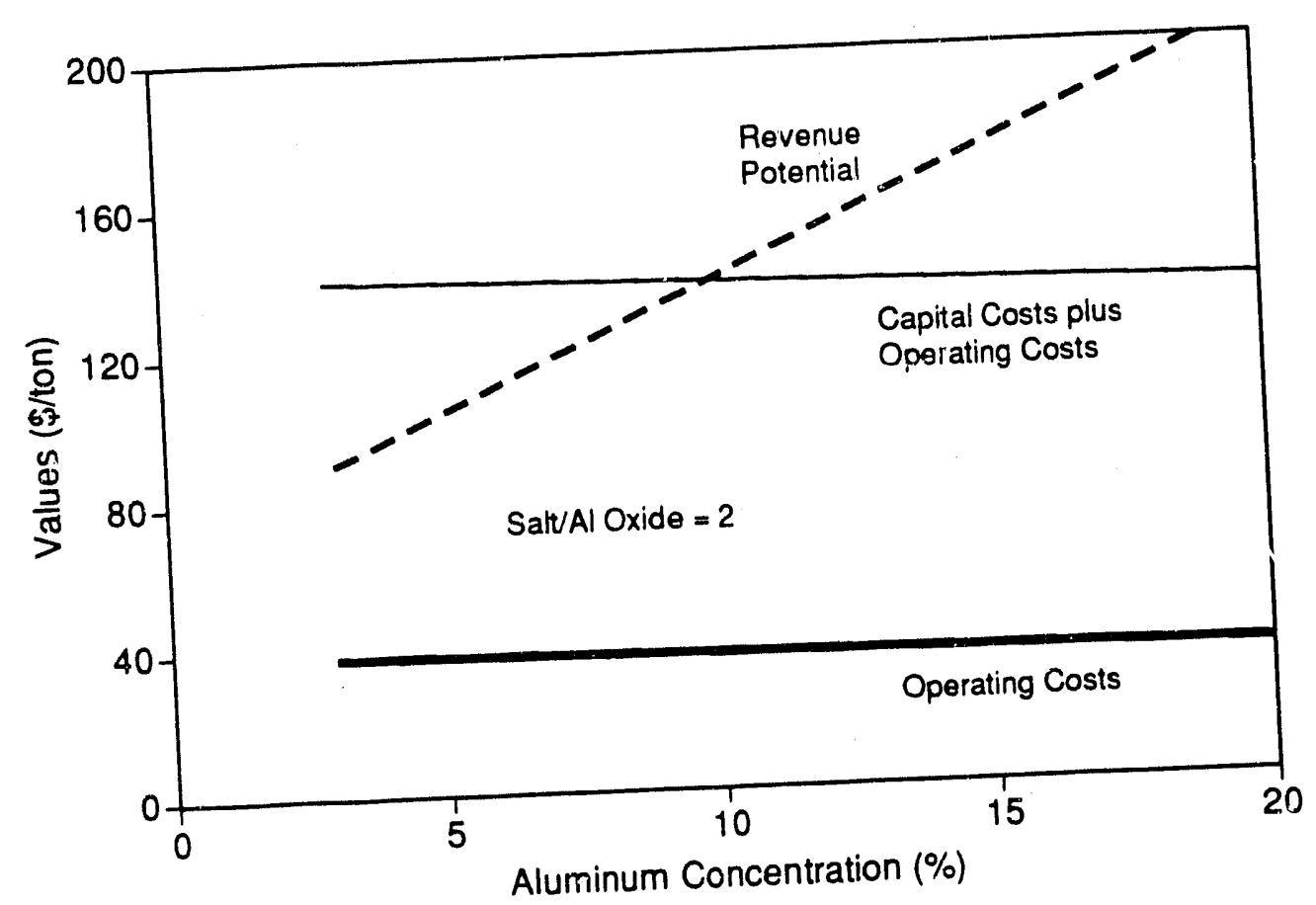

FIGURE 16 Economics of a Typical Wet-Process System vs. Aluminum Concentration

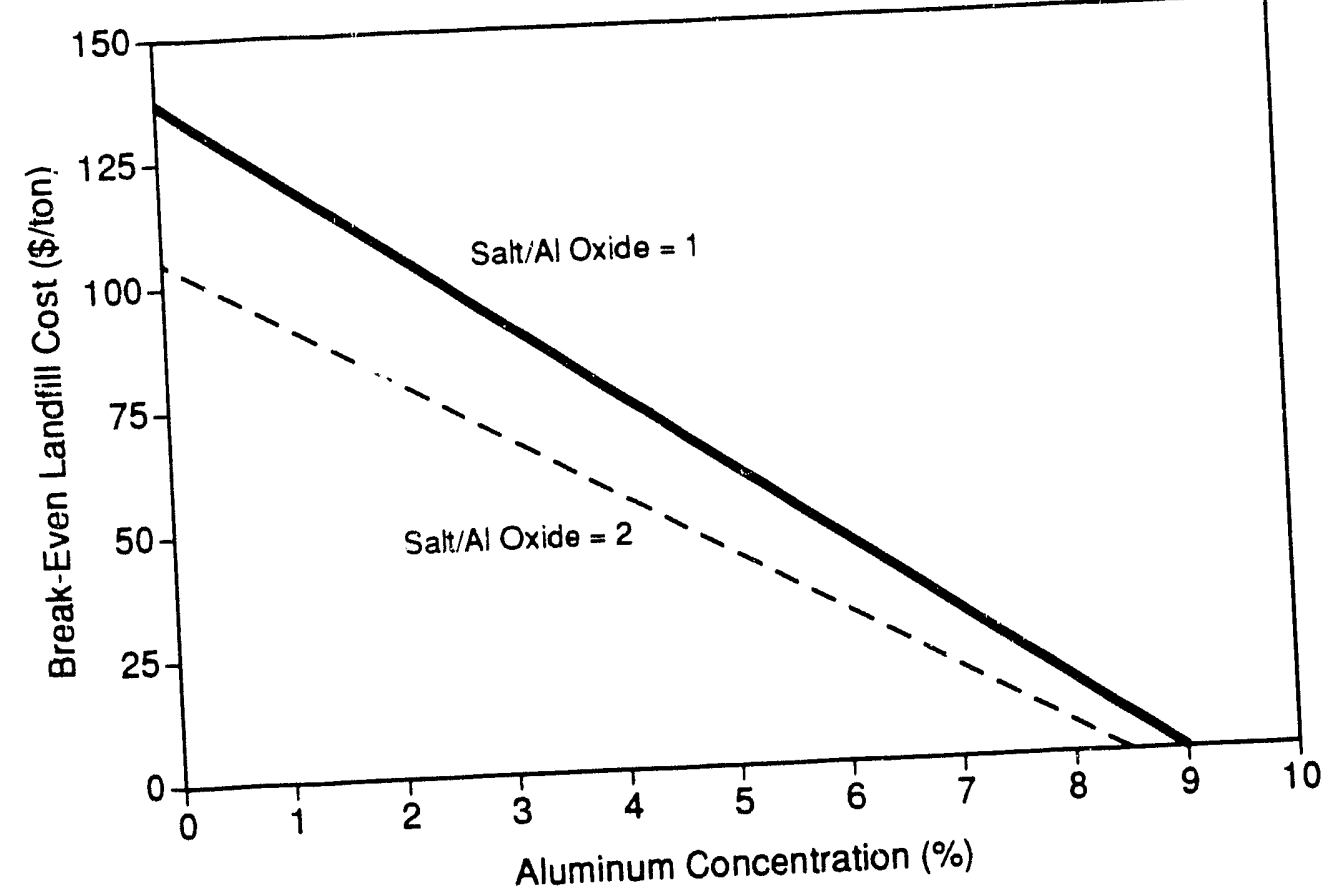

FIGURE 17 Break-Even Landfill Costs of Recycling Low-Aluminum-Conicentitiation Black Dross/Salt Cake 


\section{Conclusions and Recommendations}

The secondary aluminum industry annually disposes of large amounts of dross residues and salt cake from aluminum-dross milling operations and treatment furnaces. The increasing number of environmental regulations (with respect to the generation and disposal of industrial wastes) will likely restrict the disposal of wastes in conventional landfills. Alternative processes exist by which the constituents of the various drosses and salt cake can be recovered for recycling. European and U.S. manufacturers are currently testing and have in operation technically feasible systems that use leaching and evaporation techniques to recover and recycle the dross constituents.

The available systems require some type of milling and screening operation to recover aluminum metal and optimize the leaching process. Each system incorporates standard, commercially available equipment to minimize costs, but the engineering and subprocesses employed by each manufacturer are sometimes different. Designers often dictate the difference in the design approach on the basis of their experience with a particular process and prototypes. European scrap-aluminum smelters use rotary furnaces and generate primarily salt cake from their smelting operations. The systems developed in Europe were targeted for the processing of salt cake, although the manufacturers (B.U.S.) of the European systems claim that their systems are capable of processing black dross. The ARTS system, developed in the United States, is currently undergoing testing; according to representatives of ARTS, their system is capable of processing various grades of drosses and salt cakes generated from the primary and secondary industries.

The capital and operational costs of these systems are quite high. The processing cost (including capital) in a 60 -ton/day-capacity system will be over $\$ 80$ per metric ton of salt cake. Credit for reduced salt-cake disposal costs and revenues from recycled constituents is not included. The capital costs for such a system are estimated by Engitec to be over $\$ 5,000,000$. The above operational cost per metric ton is based on annual processed tonnage of $19.8 \times 10^{3}$ tons.

The economic justification and the market penetration of dross- and salt-cake-recycling systems in the United States are directly affected by landfill disposal costs and by revenues that are derived from recyclable (aluminum metal and salt flux) and residual materials. Landfill disposal costs per ton range from $\$ 6$ to $\$ 40$. To improve the competitiveness of existing recycling systems, research will need to be conducted in order to (1) reduce the capital costs and energy consumption of existing technologies and (2) increase the value of residual materials by developing new applications and markets for these wasted materials.

Two alternative processes - the solvent-antisolvent process and the high-pressure, hightemperature process - appear to offer the potential for cost reduction relative to conventional wetprocessing technology. Research is ongoing in order to develop the data needed to determine the technical and economic feasibility of both of these technologies. 


\section{References}

Aluminum Recycling Association, 1990, Aluminum Statistical Review for 1989, The Aluminum Recycling Association, Inc., Washington, D.C.

Aluminum Recycling Association, 1988, Facts, The Aluminum Recycling Association, Inc., Washington, D.C.

Capellini, A.R., 1980, Chapter 6 in The Handbook of Hazardous Waste Management, A.A. Metry, ed., Technomic Publishing, Westport, Conn., pp. 216-255.

Dube, S.C., and G. Dube, 1990, The Alcan Plasma Dross Treatment Process, A New Salt-Free Dross Processing Technology, Second International Symp., Recycling of Metals and Engineered Materials, Williamsburg, Va., Oct.

Heist, J., 1979, Freeze Crystallization, Chemical Engineering, 8(10):72-82, May.

Kirk-Othmer, 1978a, Aluminum and Alloys, Kirk-Othmer Encyclopedia of Chemical Technology, Third Ed., Vol. 2, John Wiley and Sons, Inc., New York, N.Y., pp. 135-138.

Kirk-Othmer, 1978b, Aluminum Compounds [ALX3, $\left.A l\left(N_{3}\right)_{3}\right]$ ], Kirk-Othmer Encyclopedia of Chemical Technology, Third Ed., Vol. 2, John Wiley and Sons, Inc., New York, N.Y., pp. 209-210.

Kulik, G.J., and J.C. Daley, 1990, Aluminum Dross Processing in the 90s, Proc. Second International Symp., Recycling of Metals and Engineered Materials, J.H.L. Van Linden, D.L.Stewart, Jr., and Y. Sahai, eds., The Minerals, Metals and Materials Society, Warrendale, Penn.

Linke, W.F., 1965, Solubilities, Inorganic and Metal-Organic Compounds, Vol. II, K-Z, Fourth Ed., American Cyanamid Co., Linden, N.J.

Magyar, M.J., et al., 1980, Experimental Processing of Salt Slags from an Aluminum Dross Furnace, U.S. Bureau of Mines Report RI8446, Washington, D.C.

Moskowitz, S.L., 1989, The Aluminum Recycling Association, Washington, D.C., personal communication.

Rao, S., and P.R. Dawson, 1980, A State-of-the-Art Report on Secondary Aluminum Processes with Particular Emphasis on Fluxes and Emission Control, Warren Spring Laboratory, Department of Industry, Stevenage, United Kingdom Report LR 359 (ME), 82 pp., June.

Reynolds, R.M., et al., 1990, The Engitec System for Treatment of Salt Slag from Secondary Aluminum Smelters, Proc. Second International Symp., Recycling of Metals and Engineered Materials, Pittsburgh, Penn., pp. 439-450. 
Roy, K.A., 1990, Freeze Crystallization Leaves Contaminants in the Cold, Hazmat World, 3(21):56-61, Dec.

Unger, T., and J.M. Hanrahan, 1990, Horsehead Resource Development Co., Inc., Palmerton, Penn., unpublished information, Oct.

Wefers, K., and G.M. Bell, 1972, Oxides and Hydroxides of Aluminum, Technical Paper No. 19, The Aluminum Company of America, Inc., Washington, D.C.

Yerushalmi, D., 1990, American Recovery Technology Systems, Cleveland, Ohio, personal communication. 


\section{DISTRIBUTION FOR ANL/ESD-11}

\section{Internal}

ANL Contract Copy

K.S. Macal (7)

ANL Patent Department

D. Karvelas (101)

ANL Technical Publications Services (3)

\section{External}

U.S. Department of Energy Office of Scientific and Technical Information (12) Manager, U.S. Department of Energy Chicago Operations Office ANL Libraries 

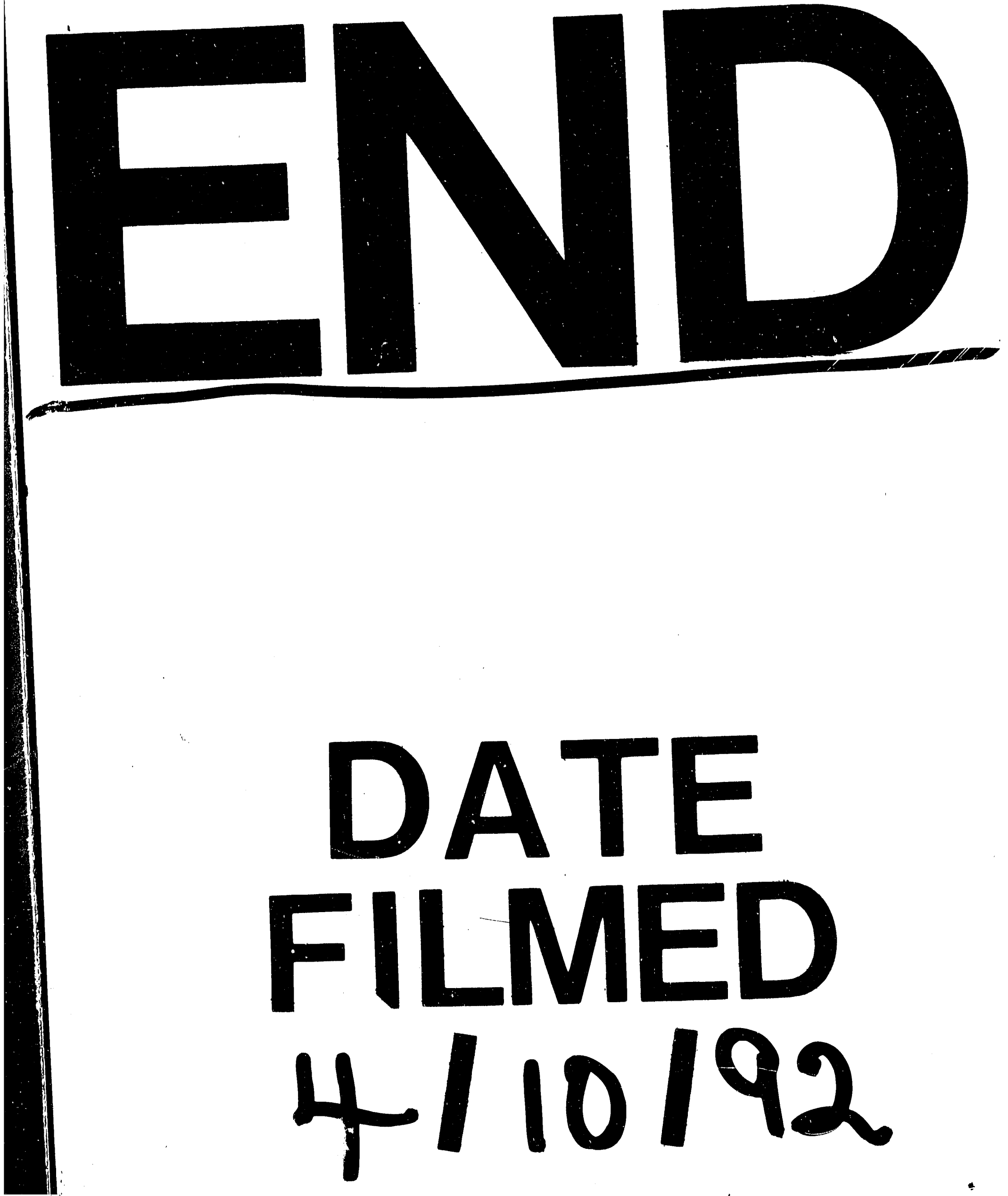
-

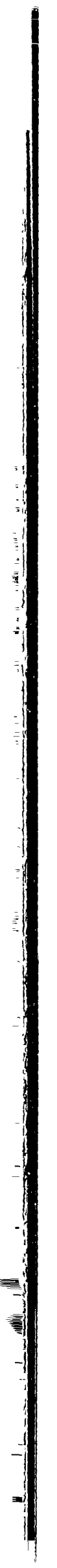

